\title{
Title: Evolution of vision and hearing modalities in theropod dinosaurs
}

Authors: Jonah N. Choiniere ${ }^{1 \dagger}$, James M. Neenan ${ }^{1,2 \dagger}$, Lars Schmitz ${ }^{3,4}$, David P. Ford ${ }^{1,}$ Kimberley E.J. Chapelle ${ }^{1,5}$, Amy M. Balanoff ${ }^{5,6}$, Justin S. Sipla ${ }^{7}$, Justin A. Georgi ${ }^{8}$, Stig A. Walsh $^{9,10}$, Mark A. Norell ${ }^{5}$, Xing Xu ${ }^{11,12}$, James M. Clark ${ }^{13}$, Roger B. J. Benson ${ }^{1,14^{*}}$

\author{
Affiliations: \\ ${ }^{1}$ Evolutionary Studies Institute, University of the Witwatersrand, 1 Jan Smuts Avenue, \\ Johannesburg 2000, South Africa \\ ${ }^{2}$ Oxford University Museum of Natural History, University of Oxford, Parks Road, Oxford, \\ OX1 3PW, UK \\ ${ }^{3}$ W.M. Keck Science Department, Claremont McKenna, Scripps, and Pitzer Colleges, 925 N \\ Mills Ave., Claremont, CA 91711, USA \\ ${ }^{4}$ Dinosaur Institute, Los Angeles County Museum of Natural History, 900 Exposition \\ Boulevard, Los Angeles, CA 90007, USA \\ ${ }^{5}$ Division of Paleontology, American Museum of Natural History, Central Park West at $79^{\text {th }}$ \\ Street, New York, NY 10024-5192, USA \\ ${ }^{6}$ Department of Psychological and Brain Sciences, Johns Hopkins University, 3400 North \\ Charles St., Baltimore, MD 21218, USA \\ ${ }^{7}$ Department of Anatomy and Cell Biology, Carver College of Medicine, University of Iowa, 51 \\ Newton Road, 100 Bowen Science Building, Iowa City, IA 52242, USA \\ ${ }^{8}$ Department of Anatomy, College of Graduate Studies, Midwestern University, 19555 N $59^{\text {th }}$ \\ Avenue, Glendale, AZ 85308, USA \\ ${ }^{9}$ Department of Natural Sciences, National Museums Scotland, Chambers Street, Edinburgh, \\ EH1 1JF, UK \\ ${ }^{10}$ School of Geosciences, University of Edinburgh, Grant Institute, Hutton Road, Edinburgh, \\ EH9 3FE, UK \\ ${ }^{11}$ Institute of Vertebrate Paleontology and Paleoanthropology, Chinese Academy of Sciences, \\ 142 Xizhimenwai Street, Beijing 100044, China, \\ ${ }^{12}$ Chinese Academy of Sciences Center for Excellence in Life and Paleoenvironment, Beijing \\ 100044, China \\ ${ }^{13}$ Department of Biological Sciences, The George Washington University, 2029 G St. NW, \\ Washington, D.C., 20052, USA \\ ${ }^{14}$ Department of Earth Sciences, University of Oxford, South Parks Road, Oxford, OX1 3AN, \\ UK \\ these authors contributed equally to this work \\ *correspondence to: roger.benson@earth.ox.ac.uk
}


Abstract: Owls and nightbirds are nocturnal hunters of active prey that combine visual and hearing adaptations to overcome limits on sensory performance in low light. Such sensory innovations are unknown in non-avialan theropod dinosaurs and are poorly characterized on the line leading to birds. We investigate morphofunctional proxies of vision and hearing in living and extinct theropods and demonstrate deep divergences of sensory modalities among groups. Nocturnal predation evolved early in the non-avialan lineage Alvarezsauroidea, signalled by extreme low-light vision and increases in hearing sensitivity. The Late Cretaceous alvarezsauroid Shuvuuia deserti also possessed specialized hearing acuity rivalling today's barn owl. This combination of sensory adaptations therefore evolved independently in dinosaurs long before the modern bird radiation, providing a striking example of convergence between dinosaurs and mammals. 


\section{Science

One Sentence Summary: Theropod dinosaurs had diverse sensory modalities, including owllike night vision and superb hearing in alvarezsauroids. 


\section{Main Text:}

Sensory specializations are some of the most striking vertebrate innovations $(1,2)$ and are common as adaptations to low-light activity in birds and mammals. Facultative nocturnal behaviors of living birds, such as tactile probing and dabbling in some water birds, require limited sensory anatomical changes (3). However, most nocturnal birds have conspicuous modifications of the visual system, and specialized nocturnal foragers of active prey combine adaptations of both vision and hearing (4). Such adaptations enable distinctive foraging strategies such as the use of precise sound-localization and low-light (scotopic) vision in the barn owl (Tyto alba), which can hunt in complete darkness (5). These sensory adaptations leave clear skeletal signatures that should be evident in fossils. Nevertheless, sensory evolution in birds and their theropod stem lineage is poorly understood (but see e.g., (6-9)). This is a substantial shortcoming in our understanding of dinosaurian biology and of the structure of Mesozoic ecosystems.

To evaluate the evolution of vison and hearing in extinct theropods, we studied skeletal proxies for two sensory systems: the scleral ossicle ring (hereafter, 'scleral ring') of the eye for vision; and the endosseous cochlear duct of the bony labyrinth for hearing. The scleral ring is embedded in the eyeball surface in numerous living and extinct amniotes. Nocturnal species typically have wider ring apertures, reflecting larger pupil sizes that increase light sensitivity (9). The endosseous cochlear duct is intimately linked to hearing performance (e.g., sensitivity, frequency range) because it houses the basilar papilla or cochlea (10). The elongate mammalian cochlea has been an area of continued evolutionary innovation (e.g., $(11,12))$, demonstrating the importance of hearing in their foraging strategies. Bird species that rely on auditory cues for foraging, such as owls, have an elongate endosseous cochlear duct, alongside other anatomical modifications (13). 
Our analyses show visual and auditory adaptations to nocturnality in alvarezsauroids, an enigmatic theropod lineage that spanned the Late Jurassic-Late Cretaceous. Early branching alvarezsauroids, such as Haplocheirus sollers, retain generalized theropod features suggesting a relatively unspecialized predatory ecology (14). However, late-branching alvarezsauroids such as Shuvuuia deserti have a curious mixture of derived traits, including bird-like skulls, cursorial hindlimbs, and short, functionally-monodactyl forelimbs interpreted as adaptations for scratchdigging $(15,16)$. These features are the source of continued speculation and debate about alvarezsauroid paleoecology (15-18).

Our digital reconstructions of the scleral rings of the alvarezsauroids Haplocheirus and Shuvuuia show a proportionally large eye with an extremely wide aperture (Fig. 1; Figs. S1-S5) (19). Phylogenetic flexible discriminant analysis (pFDA) of scleral ring and orbit morphology, extended from previous analyses (9), has mean accuracy of $92.0 \%$ for classification of extant species as nocturnal or non-nocturnal. Among theropods, the highest posterior probabilities for nocturnal vision ( $\mathrm{pp}_{\text {nocturnal }}$ ) are for Haplocheirus ( $\left.\mathrm{pp}_{\text {nocturnal }}>0.99\right)$, Shuvuuia $\left(\mathrm{pp}_{\text {nocturnal }}>0.87\right)$, and the coelophysoid Megapnosaurus (ppocturnal $>0.99$ ) (Fig. 1; Table S1). These have morphologies similar to those of birds that have specialized low-light visual systems (Fig. 1), but are different to other theropods, including many for which nocturnality was previously inferred at a much less stringent probability threshold ( $\mathrm{pp}_{\text {nocturnal }}>\mathrm{p} \mathrm{p}_{\text {diurnal }}$ or $\left.\mathrm{pp} \mathrm{p}_{\text {cathemeral }}\right)(\sigma)$.

Micro-CT scans reveals anatomical specialization of the endosseous cochlear duct in Shuvuuia, similar to the barn owl (Tyto), with large duct diameters and a proximodistally elongate morphology, curving posteromedially under the brain cavity. These anatomies are unlike almost all other theropods. Cochlear duct elongation imposes spatial constraints on the labyrinth in both taxa (Figs. 2, 3), which have low, broad semicircular canals compared to their 


\section{DIAAAS}

evolutionary relatives (20) (Fig. 3B). Both taxa also show two well-defined laminae extending along the length of the endosseous cochlear duct, medially (primary bony lamina) and laterally (secondary bony lamina) (Fig. 2). Similar laminae in mammals are attachment sites for the basilar membrane, which supports the basilar papilla.

Comparison of endosseous cochlear duct length to braincase height across 88 extant birds corroborates our interpretation of relative duct elongation as related to nocturnality and other foraging traits (Fig. 3; Table S2, Figs. S6-10) (19). Owls (Strigiformes), large-bodied, nocturnal Strisores (e.g., owlet nightjars, pootoos, frogmouths and the echolocating oilbird), and some other taxa have moderately or greatly elongated ducts (Fig. 3), whereas vocal learners do not (Fig. S6; Table S3). This suggests that duct elongation is an adaptation for auditory foraging, contradicting the hypothesis that it evolved to facilitate intraspecific communication (10). Woodpeckers, which use auditory foraging of concealed insects, show limited-moderate duct elongation (Table S3). Some water-associated birds, including gannets, kingfishers, and cormorants also show moderate duct elongation that deserves further investigation (Table S3). Nightjars, which are low-light predators of aerial prey in generally open environments, show only limited duct elongation (Table S3).

Elongation of the endosseous cochlear duct also occurs among Mesozoic theropods, including some predatory groups (Troodontidae, Tyrannosauridae, Dromaeosauridae), the secondarily herbivorous Therizinosauria, and in alvarezsauroids, including the Jurassic-Early Cretaceous taxa Haplocheirus and Xiyunykus (Fig. 3). The barn owl (Tyto), Shuvuuia and an undescribed troodontid (IGM 100/1126) are outliers, demonstrating auditory specialization, even compared to other owls, strisorans and Mesozoic theropods (Fig. 2; (20)). Proportional reduction 
of the ensosseous cochlear duct occurs in oviraptorosaurs and ornithomimosaurs, which are hypothesized to be herbivores or omnivores $(22,23)$.

The proportionally large eyes and scleral ring apertures of Haplocheirus and Shuvuuia indicate nocturnal visual adaptation. These represent some of the earliest and latest alvarezsauroids, suggesting that nocturnal visual capabilities were widespread in that group. The early appearance and phylogenetic retention of nocturnal visual adaptations in alvarezsauroids contrasts with inferences of equivocal or diurnal activity patterns in most other theropods, including early birds (Avialae) (Fig. 4). This distribution suggests a deep evolutionary divergence of activity patterns among theropods, with alvarezsauroids becoming nocturnal visual specialists (Fig. 4). The hearing-related anatomy of Shuvuuia, comprising an exceptionally elongate endosseous cochlear duct and the presence of a secondary bony lamina, is uniquely comparable to the barn owl among extant birds (Fig. 2) and corroborates the hypothesis of specialized nocturnal foraging in alvarezsauroids. This mode of life is rare in birds (4), and we also find that it was rare in non-avialan theropods, contrasting with the relatively high incidence of nocturnal foraging in mammals (24).

Even moderate elongation of the endosseous cochlear duct is rare in our broad sample of extant birds (Fig. 3D). It occurs most frequently (though not exclusively) in owls and largebodied nightbirds such as frogmouths, owlet nightjars and pootoos (Table S3). These are predominantly nocturnal predators of highly mobile and often cryptic, ground-based, and nearperch prey (3). Many of these taxa forage for prey items that were also available to extinct theropod dinosaurs (including terrestrial invertebrates and small vertebrates) by ground-running and pouncing from a low perch (e.g., frogmouths) or descent from quartering flight (e.g., owls) (3). Increased hearing ability in these groups is an adaptation that improves the chances of 
locating and successfully striking prey in low light (5). For example, the specialized hearing of barn owls, which have highly elongated duct lengths, even compared to other strigiforms, enables them to catch prey with high accuracy in complete darkness based on acoustic cues alone $(25,26)$.

In contrast to its scarcity in extant birds, moderate elongation of the endosseous cochlear duct is common in our sample of non-avialan theropods, occurring in all alvarezsauroids, the hypercarnivorous Tyrannosauridae, Dromaeosauridae, and Troodontidae, and the secondarily herbivorous Therizinosauria (Fig. 3). Theropods therefore evolved increased hearing ability more frequently than in modern birds, although Oviraptoridae and Ornithomimidae have shorter ducts (Fig. 3) and may have relied on other senses.

Previous hypotheses of alvarezsauroid ecology $(15,16,27)$ noted a unique combination of ecomorphological traits in geologically younger taxa such as Shuvuuia. These traits include dental reduction and a slender mandible, combined with fossorial adaptations of its forelimbs and have been used to support hypotheses of specialized predation on colonial insects $(15,16)$. Our study additionally indicates low-light vision and specialized auditory capabilities, traits that are widespread among mammals but rare in dinosaurs, including birds. Myrmecophagous mammals have previously been suggested as analogues for alvarezsauroids $(15,16)$. However, we note that nocturnality, excellent hearing, and digging forelimbs occur much more widely, in mammals that span a broad range of ecologies. Moreover, dental/mandibular reduction in mammals may not be a functional analogue of dental/mandibular reduction in birds and other dinosaurs: extant birds with proportionally small crania/mandibles, such as galliforms, can have wide-ranging diets, and birds that consume small vertebrates can subdue their prey without the use of teeth. We therefore suggest that derived alvarezsauroids such as Shuvuuia could have consumed a wide range of 


\section{DIAAAS}

nocturnal invertebrates and potentially small vertebrates, and that fossorially-adapted forelimbs had versatile functions, allowing excavation of shallow burrowing or crevice-inhabiting animals from the substrate or vegetation.

Combined visual and auditory specializations for nocturnality evolved independently in mammals, birds and, as reported in this study, non-avialan dinosaurs, providing an example of convergent sensory evolution in vertebrates. Sensory paleoecology of dinosaurs remains poorly understood in general. Nevertheless, our findings provide information on deep evolutionary divergences of activity patterns among non-avialan theropods and strong evidence for nocturnal specialization through 95 million years of alvarezsauroid evolution. Many living animals are active at night, but nocturnal communities remain poorly studied both today (28) and in the past. Identifying specialized night-foragers like Shuvuuia highlights the occurrence of diel partitioning among predators in Mesozoic terrestrial ecosystems. It indicates that richly sampled paleoecosystems like the Djadokhta Formation hosted previously unrecognized nocturnal and diurnal subcommunities and expands our understanding of the structure of past ecosystems and of the ecological traits of theropod dinosaurs. 

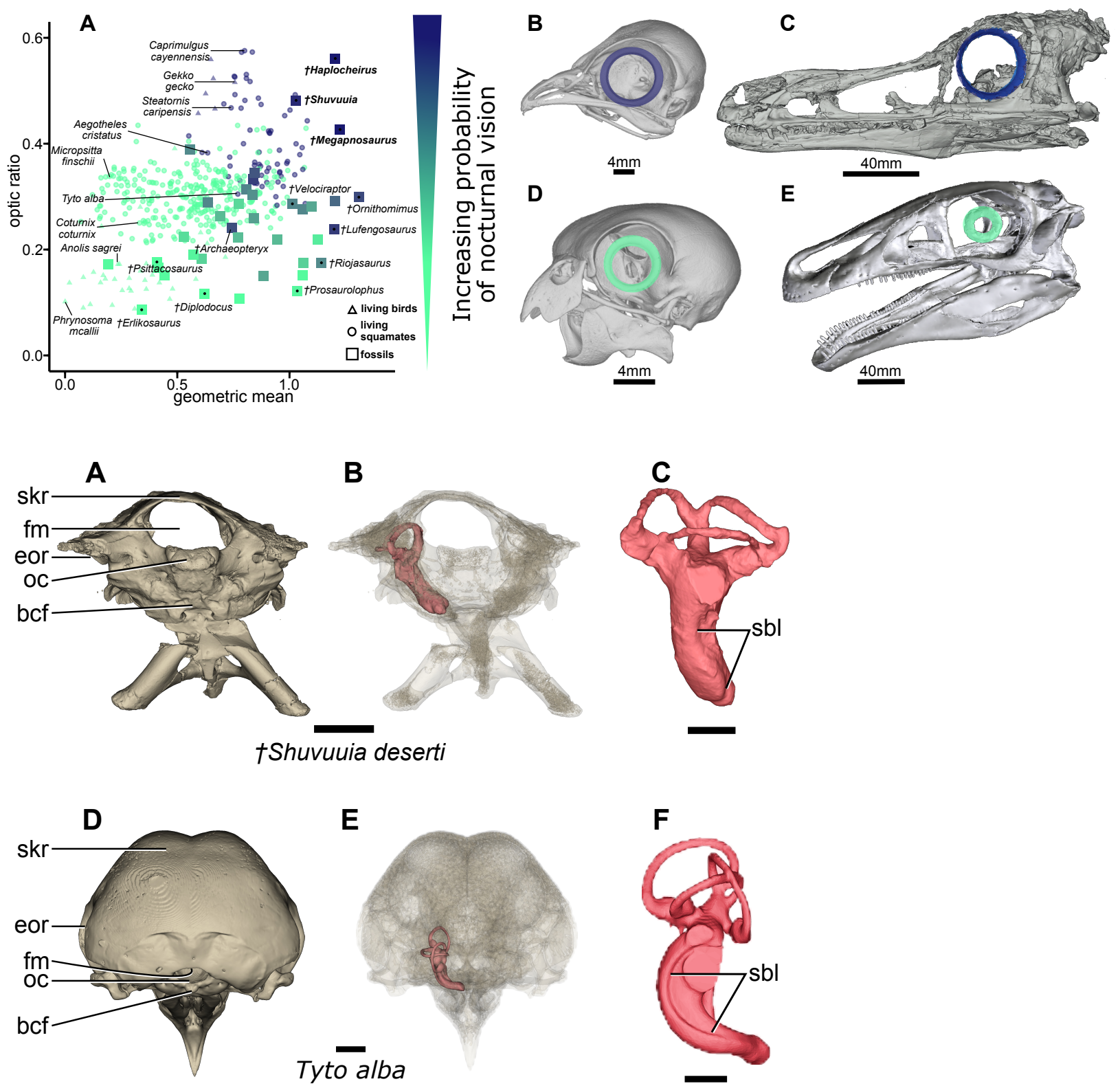

E

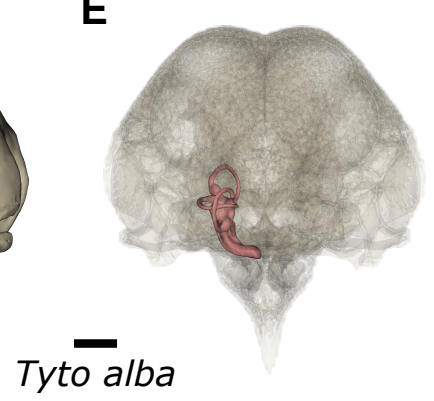

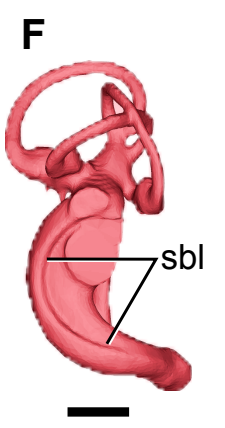




\section{MIAAAS}

A
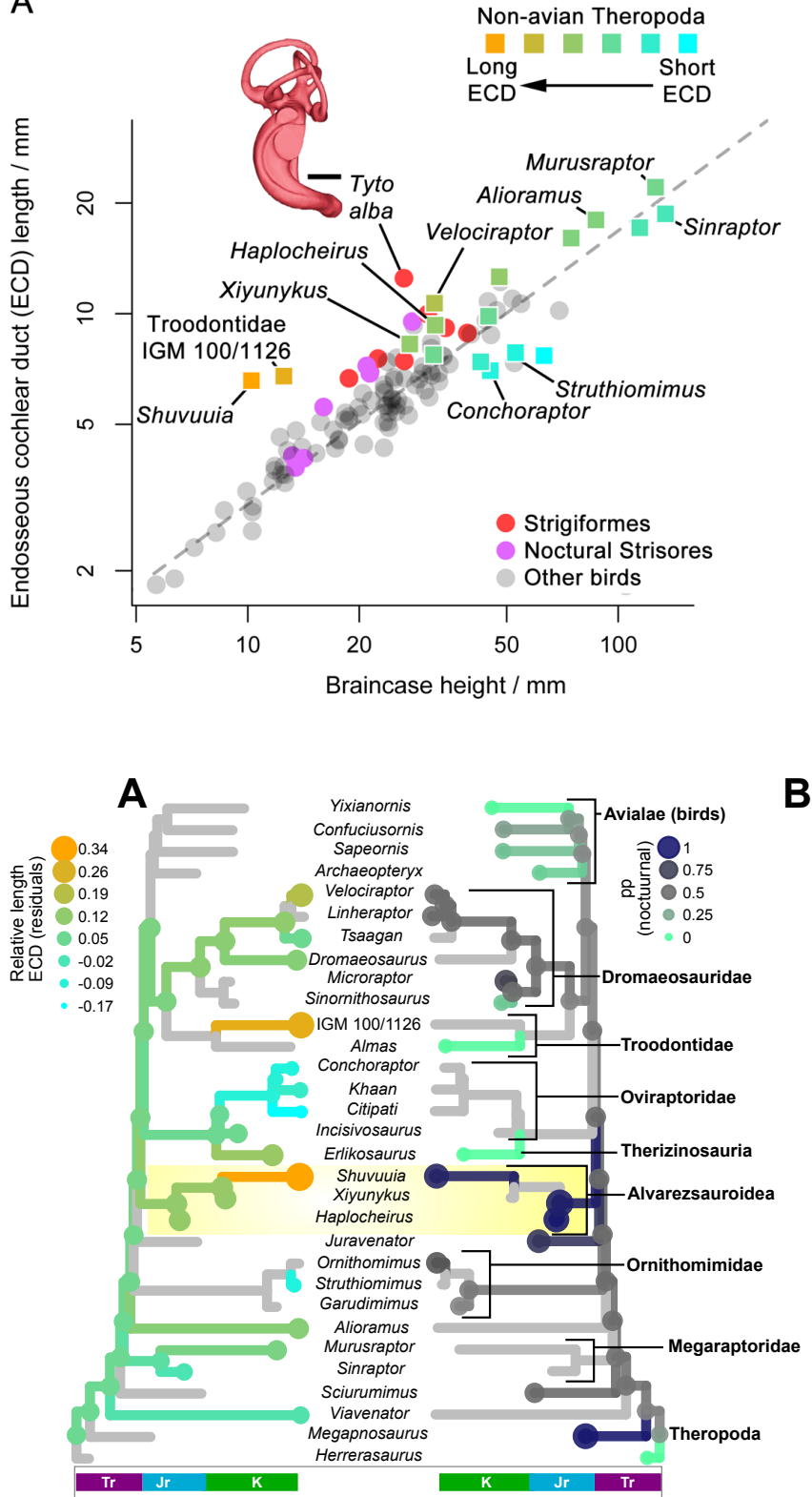

B
B

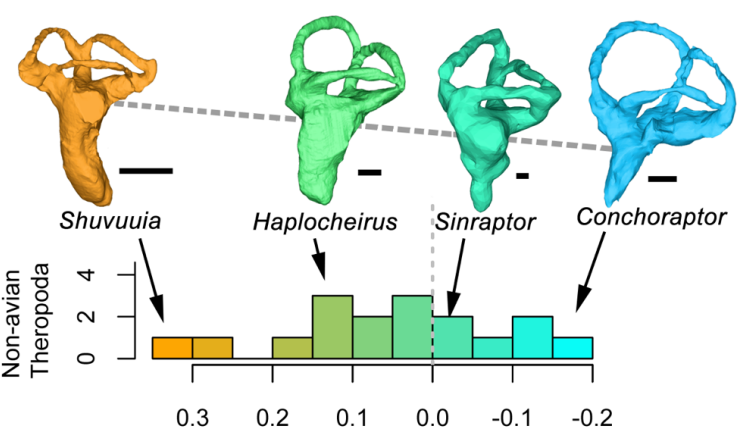

D

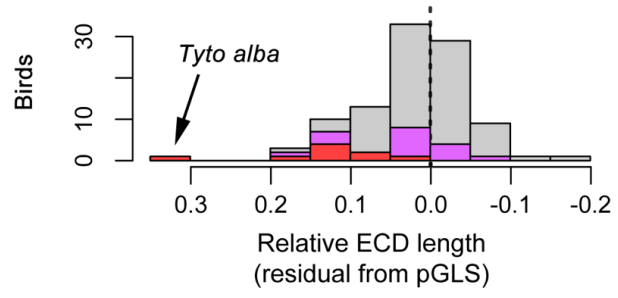

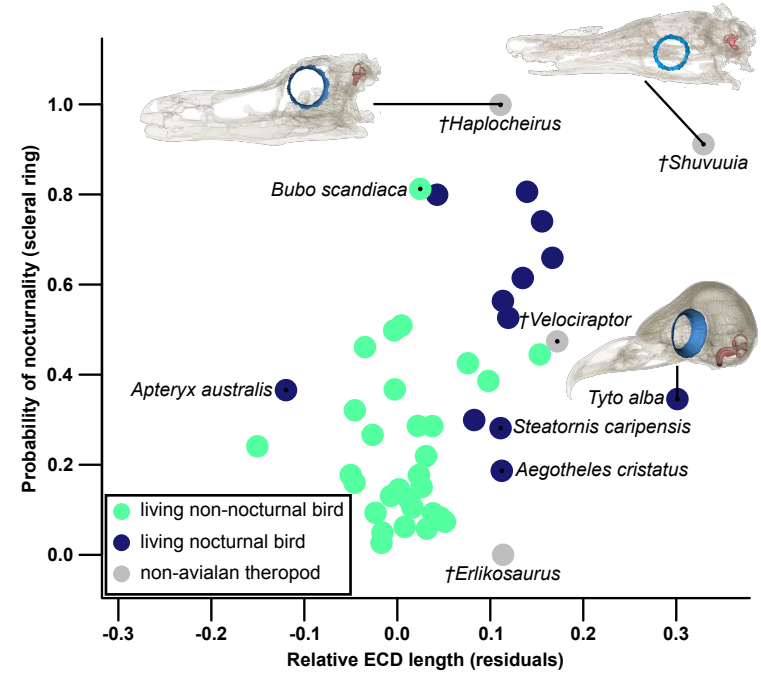


Figure Captions

Fig. 1. Optic ratio by geometric mean of optic measurements for living birds, squamates, and non-avialan theropods (A, see Data S3). Scleral ossicle ring anatomy in: B, Aegotheles cristatus; C, Haplocheirus sollers; D, Micropsitta finchii; E, Erlikosaurus andrewsi (29). Blue indicates nocturnality, green indicates non-nocturnality, color gradient indicates the posterior probability of nocturnality (19, Data S3).

Fig. 2. Comparative anatomy of the endosseous cochlear duct of Shuvuuia deserti (uncrushed adult specimen IGM100/1304; A-C) and the extant barn owl Tyto alba (D-F). A, D, posterior views of braincases showing external anatomy. B, E, transparent CT renderings of braincase in posterior view, showing endosseous labyrinths. $\mathbf{C}, \mathbf{F}$, digital reconstructions of the endosseous labyrinths in lateral view. Scale bars equal $5 \mathrm{~mm}(\mathrm{~B}, \mathrm{E}), 2.5 \mathrm{~mm}(\mathrm{C}, \mathrm{F})$. Abbreviations: bcf, braincase floor; eor, external otic region; fm, foramen magnum; oc, occipital condyle; sbl, secondary bony lamina; skr, skull roof.

Fig. 3. Endosseous cochlear duct (ECD) length in a sample of birds and non-avialan theropod dinosaurs. A, ECD length versus braincase height for extant birds (regression line $\log _{10}($ ECD length $)=-0.265+0.744 * \log _{10}($ braincase height $\left.)\right) ; p<0.0001 ; \lambda$ [phylogenetic signal] $=0.89 ; \mathrm{N}=88$ ). Residuals indicate relative duct length, indicated with a color gradient for non-avialan theropods. B, Endosseous labryinths of selected non-avialan theropods colored according to residual duct length. Grey line follows the fenestra ovalis. $\mathbf{C}-\mathbf{D}$, Histograms showing relative duct lengths among sampled extant birds (C) and non-avialan theropods (D). Scale bars equal $2.5 \mathrm{~mm}$.

Fig. 4. Endosseous cochlear duct (ECD) length residuals and pp noct for selected theropods. A, Phylogeny of study sample mapping duct length residuals and posterior probability of nocturnality in Mesozoic theropods. B, pp noct versus relative ECD length (residuals) for extant and extinct theropods. Skulls (clockwise): Haplocheirus sollers (IVPP V15988); Shuvuuia deserti (IGM100/0977; labyrinth from IGM100/1304); Tyto alba. See also Figs. S8, S9. 


\section{Science

Supplementary Materials:

Materials and Methods

Figures S1-S11

Tables S1-S3

External Data S1-S12

References (29-47) 


\section{References and Notes}

1. J. Müller, C. Bickelmann, G. Sobral. Annual Review of Earth and Planetary Sciences 46, 495519 (2018).

2. G. Schlosser. Integrative and Comparative Biology 58, 301-316 (2018).

3. G. Jones, E. C. Teeling. Trends in Ecology \& Evolution 21, 149-156 (2006).

3. G. Martin. (A\&C Black, 2010).

4. G. R. Martin. Journal of Ornithology 153, 23-48 (2012).

5. R. S. Payne, W. Drury. Nat. Hist 67, 316-323 (1958).

6. L. Schmitz, R. Motani. Science 332, $705-708$ (2011).

7. D. K. Zelenitsky, F. Therrien, R. C. Ridgely, A. R. McGee, L. M. Witmer. Proceedings of the Royal Society B: Biological Sciences 278, 3625-3634 (2011).

8. Y. Wu, H. Wang. Proceedings of the Royal Society B: Biological Sciences 286, 20182185 (2019).

9. L. Schmitz, R. Motani. Vision Research, [doi: 10.1016/j.visres.2010.1003.1009] (2010).

10. S. A. Walsh, P. M. Barrett, A. C. Milner, G. Manley, L. M. Witmer. Proceedings of the Royal Society B: Biological Sciences 276, 1355-1360 (2009).

11. E. G. Ekdale. Journal of Anatomy 228, 324-337 (2016).

12. Z.-X. Luo, J. A. Schultz, E. G. Ekdale, in Evolution of the vertebrate ear. (Springer, 2016), pp. 139-174.

13. O. Gleich, U. Langemann. Hearing research 273, 80-88 (2011).

14. J. N. Choiniere et al. Science 327, 571-574 (2010).

15. P. Senter. Paleobiology 31, 373-381 (2005).

16. N. R. Longrich, P. J. Currie. Cretaceous Research 30, 239-252 (2008).

17. F. L. Agnolin, J. E. Powell, F. E. Novas, M. Kundrat. Cretaceous Research 35, 33-56 (2012).

18. J. N. Choiniere, J. M. Clark, M. A. Norell, X. Xu. American Museum Novitates 3816, 44 (2014).

19. Materials and methods are available as supplementary materials at the Science website

20. R. B. Benson, E. Starmer-Jones, R. A. Close, S. A. Walsh. Journal of Anatomy 231, 9901018 (2017).

21. O. Gleich, R. J. Dooling, G. A. Manley. Naturwissenschaften 92, 595-598 (2005).

22. L. E. Zanno, P. J. Makovicky. Proceedings of the National Academy of Sciences 108, 232237 (2011).

23. P. M. Barrett. Annual Review of Earth and Planetary Sciences 42, 207-230 (2014).

24. K. E. Jones et al. Ecology 90, 2648-2648 (2009).

25. R. S. Payne. Journal of Experimental Biology 54, 535-573 (1971).

26. M. Konishi. American Scientist 61, 414-424 (1973).

27. A. Perle, L. M. Chiappe, R. Barsbold, J. M. Clark, M. Norell. American Museum Novitates 3105, 1-29 (1994).

28. K. J. Gaston. The American Naturalist 193, 481-502 (2019).

29. S. Lautenschlager, L. M. Witmer, P. Altangerel, L. E. Zanno, E. J. Rayfield. Journal of Vertebrate Paleontology 34, 1263-1291 (2014).

30. L. Schmitz. Journal of Morphology 270, $759-773$ (2009).

31. S. J. Hackett et al. Science 320, 1763-1768 (2008).

32. W. Jetz, G. H. Thomas, J. B. Joy, K. Hartmann, A. O. Mooers. Nature 491, 444-448 (2012). 
33. Y. Zheng, J. J. Wiens. Molecular phylogenetics and evolution 94, 537-547 (2016).

34. R. B. J. Benson et al. PLoS One 12, e1001896 (2014).

35. R. B. Benson, R. A. Frigot, A. Goswami, B. Andres, R. J. Butler. Nature communications 5, 1-8 (2014).

36. B. Andres, T. S. Myers. Earth and Environmental Science Transactions of the Royal Society of Edinburgh 103, 383-398 (2013).

37. D. W. Bapst, in Modern phylogenetic comparative methods and their application in evolutionary biology. (Springer, 2014), pp. 515-544.

38. S. W. Evers et al. Zoological Journal of the Linnean Society 187, 800-828 (2019).

39. A. Grafen. Philosophical Transactions of the Royal Society of London. Series B, Biological Sciences 326, 119-157 (1989).

40. K. T. J. Davies, P. J. J. Bates, I. Maryanto, J. A. Cotton, S. J. Rossiter. PLoS One 8, e61998 (2013).

41. J. Pinheiro, D. Bates, S. DebRoy, D. Sarkar, R. C. Team. R package version 3.1-139, (2019).

42. M. Pagel. Nature 401, (1999).

43. E. Paradis, K. Schliep. Bioinformatics 35, 526-528 (2018).

44. X. Xu et al. Current Biology 28, 2853-2860 (2018).

45. R. C. team. (R Foundation for Statistical Computing, Vienna, 2013).

46. E. Paradis, K. Schliep. Bioinformatics 35, 526-528 (2019).

47. N. J. Nagelkerke. Biometrika 78, 691-692 (1991). 
Acknowledgments: Radiology Department of the Stony Brook University Hospital, Stephan Lautenschlager, Ariana Paulina-Carabajal, Leonardo Filippi, Philip Currie, and Paul Barrett for scan data (NERC NE/E008380/1). Volume Graphics, Thermo Fisher Scientific (Amira), and Materialise (Mimics) for facilitating home licenses. Catherine Carr for discussions of hearing physiology. All data described in this paper, including measurements, models, and provenance information for fossil specimens, are available in the Supplementary Materials and at the following link: https://osf.io/gxvdc/?view_only=e45e029daed24c50ada38ee1 fbb2892d

\section{Funding:}

European Union's Horizon 2020 research and innovation programme 2014-2018, starting grant (RBJB; 677774)

Leverhulme Trust (JMN; ECF-2017-360)

NERC (SW; NE/H012176/1)

National Research Foundation of South Africa (JNC; 118994; 98800; 95449)

Kalbfleish Fellowship through the Richard Gilder Graduate School of the American Museum of Natural History (JNC; KEJC)

the National Natural Science Foundation of China (XX; 41688103)

Strategic Priority, Research Program of the Chinese Academy of Sciences (XX; XDB18000000)

National Science Foundation of the USA (AB; MAN; JMC; DEB 1801224;

EAR 1636753)

Paleontological Scientific Trust (JNC; KEJC)

DSI/NSF Center of Excellence Paleosciences (JNC; KEJC)

Jurassic Foundation (JS, JG)

Author contributions: Initials are in author order and do not reflect degree of contribution

Conceptualization: JNC, JMN, RBJB, LS

Methodology: JNC, JMN, LS, DPF, KEJC, RBJB

Software: JMN, LS, RBJB

Validation: JNC, LS, RBJB

Formal analysis: RBJB, LS

Investigation: JNC, JMN, LS, AMB, JSS, JAG, SAW, RBJB

Resources: JNC, JMN, LS, AMB, JSS, JAG, SAW, MAN, XX, JMC, RBJB

Data Curation: JNC, LS, RBJB

Writing - original draft preparation: JNC, JMN, RBJB

Writing - review and editing: All authors

Visualization: JNC, JMN, LS, DPF, KEJC, RBJB 


\section{Science Submitted Manuscript: Confidential \\ МIAAAS}

Supervision: JNC, MAN, XX, JMC, RBJB

Project administration: JNC, JMN, RBJB

Funding acquisition: JNC, JMN, LS, MAN, XX, JMC, RBJB

Competing interests: the Authors declare no competing interests. 
Data and materials availability: Available at the following link:

https://osf.io/gxvdc/?view_only=e45e029daed24c50ada38ee1fbb2892d.

Models used in this study are also available at the following Morphosource links.

For new models used in this study ( $\mathrm{N}=33$ living birds; 17 non-avialan theropods):

https://www.morphosource.org/Detail/ProjectDetail/Show/project id/1096

For previously published models $(\mathrm{N}=55)$ (44) used in this study:

http://www.morphosource.org/Detail/ProjectDetail/Show/project_id/377

Contents of the data folder, file names, and relevant figures are summarized below:

\begin{tabular}{|c|c|c|c|}
\hline File/Folder name & Name & Description of contents & $\begin{array}{l}\text { Relevant } \\
\text { figure(s) }\end{array}$ \\
\hline Extant bird labyrinth models.zip & Data S1 & $\begin{array}{l}\text { A zipped folder containing } \\
33 \text {.stl models of } \\
\text { living bird inner } \\
\text { ears that are new to } \\
\text { this study }\end{array}$ & $\begin{array}{r}2,3,4, \mathrm{~S} 4, \mathrm{~S} 5 \\
\mathrm{~S} 6, \mathrm{~S} 7 \\
\mathrm{~S} 10\end{array}$ \\
\hline $\begin{array}{l}\text { Extinct theropod labyrinth } \\
\text { models.zip }\end{array}$ & Data S2 & $\begin{array}{l}\text { A zipped folder containing } \\
17 . \text { stl models of } \\
\text { extinct theropod } \\
\text { inner ears }\end{array}$ & $\begin{array}{r}2,3,4, \mathrm{~S} 4, \mathrm{~S} 5 \\
\mathrm{~S} 6, \mathrm{~S} 7 \\
\mathrm{~S} 10\end{array}$ \\
\hline Eye_data.csv & Data S3 & $\begin{array}{c}\text { A spreadsheet containing } \\
\text { measured optical } \\
\text { variables for all } \\
\text { analysis taxa } \\
\end{array}$ & $1,4, \mathrm{~S} 3, \mathrm{~S} 8, \mathrm{~S} 9$ \\
\hline $\begin{array}{l}\text { Lagenar length measurement } \\
\text { dataset.xlsx }\end{array}$ & Data S4 & $\begin{array}{l}\text { Spreadsheet containing } \\
\text { taxonomic } \\
\text { information, } \\
\text { morphological } \\
\text { measurements, } \\
\text { specimen } \\
\text { accession/voucher } \\
\text { numbers, fossil } \\
\text { provenance } \\
\text { information, } \\
\text { copyright } \\
\text { information, and } \\
\text { CT scan parameters } \\
\text { for } 88 \text { extant bird } \\
\text { and } 17 \text { extinct } \\
\text { theropod inner ears }\end{array}$ & $\begin{array}{r}2,3,4, \mathrm{~S} 4, \mathrm{~S} 5 \\
\mathrm{~S} 6, \mathrm{~S} 7 \\
\mathrm{~S} 10\end{array}$ \\
\hline Haplocheirus.csv & Data S5 & $\begin{array}{l}\text { A spreadsheet containing } \\
\text { pp pocturnal values for } \\
\text { each tree and each } \\
\text { analysis iteration }\end{array}$ & $1, \mathrm{~S} 1, \mathrm{~S} 9$ \\
\hline
\end{tabular}




\begin{tabular}{|c|c|c|c|}
\hline & & $\begin{array}{l}\text { for Haplocheirus } \\
\text { sollers }\end{array}$ & \\
\hline Megapnosaurus.csv & Data S6 & $\begin{array}{l}\text { A spreadsheet containing } \\
\text { pp } p_{\text {nocturnal values for }} \\
\text { each tree and each } \\
\text { analysis iteration } \\
\text { for Megapnosaurus } \\
\text { kayentakatae }\end{array}$ & $1, \mathrm{~S} 1, \mathrm{~S} 9$ \\
\hline $\begin{array}{c}\text { Choiniere et al pFDA } \\
\text { analyses.zip }\end{array}$ & Data S7 & $\begin{array}{l}\text { A zipped folder containing } \\
\text { all data, trees, and } \\
\text { R scripts to run } \\
\text { SOR analysis, plus } \\
\text { folders containing } \\
\text { all results. A } \\
\text { readme file } \\
\text { explains how to run } \\
\text { the scripts. }\end{array}$ & 1,4 \\
\hline Shuvuuia.csv & Data S8 & $\begin{array}{l}\text { A spreadsheet containing } \\
\text { pp }_{\text {nocturnal values for }} \\
\text { each tree and each } \\
\text { analysis iteration } \\
\text { for Shuvuuia } \\
\text { deserti }\end{array}$ & $1, \mathrm{~S} 1, \mathrm{~S} 2, \mathrm{~S} 9$ \\
\hline $\begin{array}{l}\text { Supplemental Information } \\
\text { Table } 1\end{array}$ & Data S9 & $\begin{array}{l}\text { A spreadsheet containing } \\
\text { classification } \\
\text { summaries for } \\
\text { phylogenetic } \\
\text { flexible } \\
\text { discriminant } \\
\text { analyses, } \\
\text { performed over a } \\
\text { sample of } 50 \text { trees. }\end{array}$ & $1,4, \mathrm{~S} 3, \mathrm{~S} 8, \mathrm{~S} 9$ \\
\hline $\begin{array}{l}\text { Supplemental Information } \\
\text { Table } 2\end{array}$ & Data S10 & $\begin{array}{l}\text { A spreadsheet containing } \\
\text { average } \\
\text { classification errors } \\
\text { for phylogenetic } \\
\text { flexible } \\
\text { discriminant } \\
\text { analyses, broken } \\
\text { down by group of } \\
\text { diel activity pattern } \\
\text { (dap). }\end{array}$ & $1,4, \mathrm{~S} 3, \mathrm{~S} 8, \mathrm{~S} 9$ \\
\hline $\begin{array}{l}\text { Supplemental Information } \\
\text { Table } 3\end{array}$ & Data S11 & $\begin{array}{c}\text { A spreadsheet containing } \\
\text { predicted diel } \\
\text { activity pattern } \\
\text { from all analyses. }\end{array}$ & $1,4, \mathrm{~S} 3, \mathrm{~S} 8, \mathrm{~S} 9$ \\
\hline
\end{tabular}




\begin{tabular}{|c|l|l|l|}
\hline \multirow{2}{*}{$\begin{array}{c}\text { ECD data objects for Choiniere } \\
\text { et al 20201.zip }\end{array}$} & $\begin{array}{l}\text { Data sheets and analytical } \\
\text { scripts demonstrating } \\
\text { regression of ECD length on } \\
\text { skull size measures, and for } \\
\text { generating figures shown in } \\
\text { the paper and its } \\
\text { supplement }\end{array}$ & $3,4, \mathrm{S6}, \mathrm{S7}, \mathrm{S} 10$ \\
\hline
\end{tabular}

Correspondence and requests for materials should be addressed to Roger Benson, roger.benson@earth.ox.ac.uk. 


\section{Supplementary Materials for}

\section{Evolution of vision and hearing modalities in theropod dinosaurs}

Authors: Jonah N. Choiniere ${ }^{1 \dagger}$, James M. Neenan ${ }^{1,2 \dagger}$, Lars Schmitz ${ }^{3,4}$, David P. Ford ${ }^{1}$, Kimberley E.J. Chapelle ${ }^{1,5}$, Amy M. Balanoff ${ }^{5,6}$, Justin S. Sipla ${ }^{7}$, Justin A. Georgi ${ }^{8}$, Stig A.

Walsh $^{9,10}$, Mark A. Norell ${ }^{5}$, Xing Xu ${ }^{11,12}$, James M. Clark ${ }^{13}$, Roger B. J. Benson ${ }^{1,14 *}$

Correspondence to: roger.benson@earth.ox.ac.uk

\section{This PDF file includes:}

Materials and Methods

Figs. S1 to S11

Tables $\mathrm{S} 1$ to $\mathrm{S} 3$

Captions for Data S1 to S11

Other Supplementary Materials for this manuscript include the following:

Data files S1 to S11:

\begin{tabular}{|c|c|c|c|}
\hline File/Folder name & Name & Description of contents & $\begin{array}{c}\text { Relevant } \\
\text { figure(s) }\end{array}$ \\
\hline Extant bird labyrinth models.zip & Data S1 & $\begin{array}{l}\text { A zipped folder containing } \\
33 \text { stl models of } \\
\text { living bird inner } \\
\text { ears }\end{array}$ & $\begin{array}{r}2,3,4, \mathrm{~S} 4, \mathrm{~S} 5 \\
\mathrm{~S} 6, \mathrm{~S} 7 \\
\mathrm{~S} 10\end{array}$ \\
\hline $\begin{array}{l}\text { Extinct theropod labyrinth } \\
\text { models.zip }\end{array}$ & Data S2 & $\begin{array}{l}\text { A zipped folder containing } \\
17 \text {.stl models of } \\
\text { extinct theropod } \\
\text { inner ears }\end{array}$ & $\begin{array}{r}2,3,4, \mathrm{~S} 4, \mathrm{~S} 5 \\
\mathrm{~S} 6, \mathrm{~S} 7 \\
\mathrm{~S} 10\end{array}$ \\
\hline Eye_data.csv & Data S3 & $\begin{array}{c}\text { A spreadsheet containing } \\
\text { measured optical } \\
\text { variables for all } \\
\text { analysis taxa } \\
\end{array}$ & $1,4, \mathrm{~S} 3, \mathrm{~S} 8, \mathrm{~S} 9$ \\
\hline $\begin{array}{l}\text { Lagenar length measurement } \\
\text { dataset.xlsx }\end{array}$ & Data S4 & $\begin{array}{l}\text { Spreadsheet containing } \\
\text { taxonomic } \\
\text { information, } \\
\text { morphological } \\
\text { measurements, } \\
\text { specimen } \\
\text { accession/voucher }\end{array}$ & $\begin{array}{r}2,3,4, \mathrm{~S} 4, \mathrm{~S} 5 \\
\mathrm{~S} 6, \mathrm{~S} 7 \\
\mathrm{~S} 10\end{array}$ \\
\hline
\end{tabular}




\begin{tabular}{|c|c|c|c|}
\hline & & $\begin{array}{l}\text { numbers, fossil } \\
\text { provenance } \\
\text { information, } \\
\text { copyright } \\
\text { information, and } \\
\text { CT scan parameters } \\
\text { for } 88 \text { extant bird } \\
\text { and } 17 \text { extinct } \\
\text { theropod inner ears }\end{array}$ & \\
\hline Haplocheirus.csv & Data S5 & $\begin{array}{l}\text { A spreadsheet containing } \\
\text { pp } \\
\text { each tree and each } \\
\text { analysis iteration } \\
\text { for Haplocheirus } \\
\text { sollers }\end{array}$ & $1, \mathrm{~S} 1, \mathrm{~S} 9$ \\
\hline Megapnosaurus.csv & Data S6 & $\begin{array}{l}\text { A spreadsheet containing } \\
\mathrm{pp}_{\text {nocturnal values for }} \\
\text { each tree and each } \\
\text { analysis iteration } \\
\text { for Megapnosaurus } \\
\text { kayentakatae }\end{array}$ & $1, \mathrm{~S} 1, \mathrm{~S} 9$ \\
\hline Scripts_trees_data_results.zip & Data S7 & $\begin{array}{l}\text { A zipped folder containing } \\
\text { all data, trees, and } \\
\text { R scripts to run } \\
\text { SOR analysis, plus } \\
\text { folders containing } \\
\text { all results. A } \\
\text { readme file } \\
\text { explains how to run } \\
\text { the scripts. }\end{array}$ & \\
\hline Shuvuuia.csv & Data S8 & $\begin{array}{l}\text { A spreadsheet containing } \\
\text { pp pocturnal values for } \\
\text { each tree and each } \\
\text { analysis iteration } \\
\text { for Shuvuuia } \\
\text { deserti } \\
\end{array}$ & $1, \mathrm{~S} 1, \mathrm{~S} 2, \mathrm{~S} 9$ \\
\hline $\begin{array}{l}\text { Supplemental Information } \\
\text { Table } 1\end{array}$ & Data S9 & $\begin{array}{l}\text { A spreadsheet containing } \\
\text { classification } \\
\text { summaries for } \\
\text { phylogenetic } \\
\text { flexible } \\
\text { discriminant } \\
\text { analyses, } \\
\text { performed over a } \\
\text { sample of } 50 \text { trees. }\end{array}$ & $1,4, \mathrm{~S} 3, \mathrm{~S} 8, \mathrm{~S} 9$ \\
\hline $\begin{array}{l}\text { Supplemental Information } \\
\text { Table } 2\end{array}$ & Data S10 & $\begin{array}{l}\text { A spreadsheet containing } \\
\text { average } \\
\text { classification errors }\end{array}$ & $1,4, \mathrm{~S} 3, \mathrm{~S} 8, \mathrm{~S} 9$ \\
\hline
\end{tabular}




\begin{tabular}{|c|c|c|c|}
\hline & & $\begin{array}{l}\text { for phylogenetic } \\
\text { flexible } \\
\text { discriminant } \\
\text { analyses, broken } \\
\text { down by group of } \\
\text { diel activity pattern } \\
\text { (dap). }\end{array}$ & \\
\hline $\begin{array}{l}\text { Supplemental Information } \\
\text { Table } 3\end{array}$ & Data S11 & $\begin{array}{c}\text { A spreadsheet containing } \\
\text { predicted diel } \\
\text { activity pattern } \\
\text { from all analyses. }\end{array}$ & $1,4, \mathrm{~S} 3, \mathrm{~S} 8, \mathrm{~S} 9$ \\
\hline $\begin{array}{l}\text { ECD data objects for Choiniere } \\
\text { et al 20201.zip }\end{array}$ & Data S12 & $\begin{array}{l}\text { Data sheets and analytical } \\
\text { scripts demonstrating } \\
\text { regression of ECD length on } \\
\text { skull size measures, and for } \\
\text { generating figures shown in } \\
\text { the paper and its } \\
\text { supplement }\end{array}$ & $3,4, \mathrm{~S} 6, \mathrm{~S} 7, \mathrm{~S} 10$ \\
\hline
\end{tabular}




\section{Materials and Methods}

\section{$\underline{\text { Provenance of fossil specimens }}$}

Information about the provenance of fossil specimens used in this study is included in Data S4. This includes specimen numbers, locality, geological context, age and citations to relevant data sources, as well as the institutions in which they are housed and accessible.

\section{$\underline{\text { Scleral }} \underline{\text { ring reconstructions }}$}

The scleral ring of Haplocheirus sollers was reconstructed from the holotype specimen, IVPP V15988, which comprises a nearly complete skull and mandible, with no evidence of mediolateral crushing and only mild distortion posteriorly on the right side of the skull (14). The scleral ossicle rings were originally preserved in situ, with minor disarticulation, but were later damaged and required digital reconstruction. The best-preserved scleral ossicles were originally located in the left orbit (see (18) figs. 4 and 10). We segmented these from micro-computed tomographic $(\mu \mathrm{CT})$ scan data using Mimics v.19.0 x64

(http://biomedical.materialise.com/mimics). The resulting 3D digital models were used, together with data and measurements from original descriptions (14), to reconstruct the scleral ring (Fig. S1). Prior to breakage, the ring was composed of approximately 20 ossicles (18). Digital restoration of a complete scleral ring was conducted in Blender v.2.81a (https://

www.blender.org) duplicating and re-articulating an articulated series of 2.5 scleral ossicles to form a ring of 20 plates that measures $\sim 33 \mathrm{~mm}$ in internal diameter. The validity of our digital reconstruction is confirmed by comparison of our digital scleral ring to inferences from the original specimen: Choiniere et al. (18) inferred that the internal diameter of the ring was approximately $76 \%$ of the orbit diameter, whereas our measurement is $73.5 \%$ (Fig. S1D).

For the scleral ring of Shuvuuia deserti, we reconstructed $\mu$ CT Scans of IGM 100/0977 using VG Studio Max 3.3.2 (https://www.volumegraphics.com/en/products/vgstudio-max.html). We segmented the 16 associated scleral ossicles preserved in the ventral part of the right orbit (mirrored in our figures and our analysis for ease of visual comparison with Haplocheirus sollers). We selected the three best-preserved and best-articulated scleral ossicles from the 16 associated elements for further analysis and reconstruction. One of these ossicles was slightly rotated and we digitally rearticulated it to its presumed life position. Adjacent ossicles have about $30 \%$ overlap, and we used this observation to place duplicated versions of the three segmented plates into a circular shape, following the curved contours of the ossicles. This resulted in 19 plates comprising a complete scleral ring, with an estimated inner diameter of $22.36 \mathrm{~mm}$ and outer diameter of $28.33 \mathrm{~mm}$ that we consider as a maximal estimate of ring size. In total 16 scleral ossicles are preserved from the right ring, providing a minimum bound on size. Therefore, we also built a digital reconstruction with 16 ossicles, which has an inner diameter of $18.95 \mathrm{~mm}$ and an outer diameter of $24.76 \mathrm{~mm}$ (Fig. S2). This minimum ring size estimate is conservative with respect to our hypothesis that alvarezsauroids had nocturnal vision (smaller aperture sizes generally indicate diurnal habits), so we used this minimum estimate in all subsequent analyses. We view it as likely, however, that the original ring was larger than this. 
Both orbits of IGM 100/0977 are dorsoventrally crushed and the postorbital bars are disarticulated. We therefore estimated orbit diameter by comparing measurements with a smaller, uncrushed skull (IGM 100/1001). We measured the distance between the contact of the frontal with the postorbital posteriorly in the orbital rim to the contact of the frontal with the prefrontal anteriorly, indicating that the orbit of $100 / 0977$ is 1.786 times the size of that in IGM $100 / 1001$ (linear measurement $=17.17 \mathrm{~mm}$ in IGM 100/1001; $=30.37 \mathrm{~mm}$ in IGM 100/0977). We used this to scale the orbit height of IGM 100/1001 (orbit height $=16.85 \mathrm{~mm}$ ), resulting in an estimated orbit diameter of $30.1 \mathrm{~mm}$. Anteroposterior orbit length was not used because of the occurrence of an extensive preorbital extension in IGM 100/1001 that artificially extends the effective orbit diameter.

The shapes of the ossicles, the estimated number in a complete ring, and the percent occupation of the orbit in our reconstructions of Shuvuuia are all strikingly similar to those of Haplocheirus and Megapnosaurus, and are outliers relative to other non-avialan theropods.

\section{Osteological correlates of visual nocturnality}

To analyse visual adaptations to light environments we collated measurements of orbit length, outer (=external), and inner (internal) scleral ring diameter (see Fig. S3), all of which are relevant for ocular image formation (30). Data were taken from Schmitz and Motani (6) and supplemented with more data on extant birds (Data S3) and the new information for Haplocheirus and Shuvuuia (see scleral ring reconstructions in Figs. S1 and S2). This combined dataset comprises 55 extant squamates, 367 extant birds, and 37 Mesozoic archosaurs, including 14 non-avialan theropods and four Mesozoic birds (Avialae). Most extant species in this dataset are classified as diurnal $(\mathrm{N}=308$, while nocturnal species $(\mathrm{N}=75)$ and cathemeral species $(\mathrm{N}=39)$ make up much smaller proportions.

We performed phylogenetic flexible discriminant analysis (pFDA (๑)) on species average orbit and scleral ring measurements, using a time-calibrated phylogenetic framework (for R scripts see Supplemental Materials Data S7). For this analysis, we constructed a distribution of supertrees using trees with branch lengths of extant birds based on the Hackett et al. (31) backbone presented by Jetz et al. (32), and of squamates from Zheng and Wiens (33), combined with the topology of Benson et al (34) for extinct dinosaurs and Benson et al (35) (based on Andres \& Myers (36)) for pterosaurs. Fossil branch lengths were reconstructed using their stratigraphic occurrence ages and imposing a minimum branch length of $1 \mathrm{Ma}$ ("mbl1", e.g. (37)). Given the temporally-extensive distribution of fossil species, and the sparse nature of our taxon sample compared to the sizes of these phylogenies, these branch durations in the phylogeny are primarily determined by occurrences of older fossil members of each group. Therefore this timescaling approach (mbl1) yields similar divergence times to other approaches.

We accounted for phylogenetic uncertainty by iterating pFDA over a sample of 50 trees (reflecting variation in topology of the fossil source trees and variation in topology and branch lengths from the extant bird tree distribution). To test for the reliability of our diel activity inferences, we ran several different versions of the dataset (Data S5-11): 
1) pFDA training data consisting of only extant birds, three diel activity bins (scotopic/photopic/mesopic), all three originally measured traits (orbit length, outer, and inner diameter);

2) pFDA training data consisting of only extant birds, only two diel activity bins (scotopic/non-scotopic), all three originally measured traits (orbit length, outer, and inner diameter);

3) pFDA training data consisting of only extant birds, only two diel activity bins (scotopic/non-scotopic), two traits (optical ratio sensu( 8$)$ and geometric mean of all traits;

4) pFDA training data consisting of extant birds and lizards, three diel activity bins (scotopic/photopic/mesopic), all three originally measured traits (orbit length, outer, and inner diameter);

5) pFDA training data consisting of extant birds and lizards, only two diel activity bins (scotopic/non-scotopic), all three originally measured traits (orbit length, outer, and inner diameter);

6) pFDA training data consisting of extant birds and lizards, only two diel activity bins (scotopic/non-scotopic), two traits (optical ratio sensu( 8$)$ and geometric mean of all traits.

All pFDA iterations followed the same approach: determine optimal lambda for correlations between traits and behavior, extract correct classification rates, apply discriminant function to fossils, and record bin predictions with posterior probabilities (see Supplemental Information). Analysis 5 yielded the best classification rates ( $92 \%$ correct, averaged over 50 trees; see Data S7). Adding squamates to the analysis improved the classification accuracy by about 2-3\%. Analyses 2 and 4 follow the same approach but analysis 4 is based on birds and squamates as extant comparisons, and the error rate decreases from 10 to $8 \%$. It is not clear whether this error reduction is due to adding a phylogenetically more distant clade or represents an effect of larger sample size. Throughout all analyses, false classifications as nocturnal tended to be rare. For example, for analysis 5 , only $5 \%$ of non-nocturnal species were erroneously classified as nocturnal, while $20 \%$ of nocturnal species were grouped in the non-nocturnal category (see Data S7). This classification pattern suggests that inferences of nocturnality may be conservative. Correct classifications of cathemeral activity for training taxa were entirely absent in both analyses that employed a three-group diel activity pattern approach (analyses 1 and 3 ). $\mathrm{R}$ scripts, classifications of fossils based on posterior probabilities averaged over 50 iterations, and all predicted bins are available in Data S7.

\section{Inference of hearing ability}

To examine the hearing ability of alvarezsaurs and other theropods, we collected $\mu \mathrm{CT}$ scans of 74 birds and 17 non-avialan theropods (including the alvarezsauroids Haplocheirus sollers IVPP V15988, Xiyunykus pengi IVPP V22783, and Shuvuuia deserti IGM 100/1304), and reconstructed the endosseous cochlear duct for each using VG Studio Max v3.2 and Amira 2019.1 (see Figs. S8, S9; Data S4). Endosseous cochlear ducts from the left labyrinth were used 
in all birds and non-avialan theropods (in some taxa the right labyrinth was used and reflected owing to better preservation). Relative endosseous cochlear duct lengths have previously been shown to correlate with hearing frequency range, in a study that scaled duct lengths in various reptiles, including birds, based on basicranial length (10). We do not attempt to estimate hearing frequency range for extinct taxa here but nevertheless consider the relative duct length to be a generalized proxy for auditory specialization.

Our CT scans of fossil specimens were screened prior to use to ensure that scan quality and specimen preservation were sufficient to ensure representative measurements of endosseous cochlear duct length. Among CT datasets that were available to us prior to analysis, we excluded any that showed substantive crushing (especially dorsoventral crushing) of the braincase that would modify the original duct length or braincase height. We also confirmed that the duct lengths in these models reflected the in-life anatomy by critical examination of the relevant portions of the braincase. Finally, we excluded scans where the endosseous cochlear duct was not sufficiently well-preserved, or lacked sufficient resolution or visualisation quality to provide a representative measurement.

To obtain accurate midline lengths, each endosseous cochlear duct was skeletonized using the Auto Skeleton tool in Amira, according to the methods outlined in $(20,38)$. Semilandmarks were placed using Amira along each skeletonized duct, starting from the narrowest point where the lagena meets the vestibule, along the entire course, and then a final landmark was placed on the most distal point of the external surface (Fig. S6).

To statistically determine the best size measurement for indexing the relative length of the endosseous cochlear duct, we performed a set of phylogenetic regressions (39) of $\log _{10}$ (duct length) on: (1) braincase height, approximating the size of the vertical space available to accommodate the vestibular organ; (2) hindbrain height, representing the height of the posterior portion of the brain; (3) braincase width, representing an alternative measure of braincase size as an estimate of space available to accommodate the vestibular organ; (4) species body mass; and (5) postrostral length, being the skull length measured excluding the rostrum (i.e. from the anterior orbit margin to the level of the occipital condyle). Postrostral length provides a measure of overall skull size when excluding the rostrum, which varies substantially in cross-sectional area and mass among birds. Postrostral length was only available for $\mathrm{N}=71$ of our total sample of $\mathrm{N}=88$ species. We therefore conducted two sets of analyses, one at each sample size. We compared these models using AICc (Akaike's information criterion for finite sample sizes), allowing the data to indicate which provides the best explanation of absolute duct length.

This analysis provides decisive support for indexing relative endosseous cochlear duct length against braincase height (Table S2; $\triangle \mathrm{AICc}>12 ; \mathrm{R}^{2}>0.75$ ), measured as the distance between the ventral surface of the basisphenoid to the highest point on the dorsal surface of the cranial vault (usually the frontal; Fig. S7). We chose this measurement as an estimate of the relative space available to accommodate the vertical height of the endosseous labyrinth, and therefore to house an elongate endosseous cochlear duct. Our model comparison results provide 
strong evidence that braincase height represents a structural limit on duct length in birds, and that auditory specialists should have positive residuals from this relationship.

The hypothesis that braincase height provides a structural limit on endosseous cochlear duct length is also supported by the existence of trade-offs between duct length and the size of the vestibular organ (comprising the dorsal part of the labyrinth) in taxa which have elongate endosseous cochlear ducts. This trade-off suggests that extreme duct elongation imposes constraints on the vertical space available to house the semicircular canals, and has been demonstrated so far in echolocating bats (40) and in barn owls (20) (also see main text Figs 2, 3, showing that Shuvuuia has a dorsoventrally compressed semicircular canal geometries, suggesting that endosseous cochlear duct elongation has imposed a constraint on the dorsoventral space available for the SCCs).

Our phylogenetic regressions were implemented using the gls () function of the R package nlme version 3.1-139 (41), estimating Pagel's $\lambda$, a phylogenetic signal parameter (42) to vary during fitting of the regression model using the corPagel correlation structure of ape version 5.0 (43). We used 100 trees from the tree distribution of Jetz et al. (32) for this analysis, based on the Hackett backbone (31) and present mean values from across those analyses in our results tables. Residuals from the resulting regression line were used as a measure of relative ECD length in both birds and non-avialan theropods (see Figs. S8, S9 and Table S3, Supplemental Information).

Although the specimen of Shuvuuia used for the scleral ring reconstruction (IGM100/0977) is dorsoventrally crushed (see main text Fig. 4, and Fig. S2), the ECD reconstruction and the braincase measurements for this taxon were made using a similar-sized, undistorted specimen (IGM 100/1304; main text Fig. 2). The braincase of Xiyunykus pengi IVPP V22783 is incomplete, as it lacks the supraoccipitals and parietals (44). It was therefore necessary to estimate braincase height for this taxon based on the preserved portions (basioccipital, basisphenoid and exoccipital/opisthotics). To do this, we took measurements of corresponding braincase elements from the alvarezsauroids Haplocheirus sollers (IVPP V15988) and Shuvuuia deserti (IGM 100/1304). We specifically compared the height from the posteromedial point of the basal tuber to the posterodorsal point of the exoccipital. These measurements suggest that the braincase of Xiyunykus is 0.86 times the size of that in Haplocheirus (braincase height $=32.0 \mathrm{~mm}$ ) and 2.67 times that of Shuvuuia (braincase height $=$ $10.2 \mathrm{~mm}$ ). This results in estimated braincase heights for Xiyunykus of $27.5 \mathrm{~mm}$ and $27.2 \mathrm{~mm}$. Because of the similarity in these values we used a braincase height of $27.35 \mathrm{~mm}$ for Xiyunykus.

\section{Qualitative analysis of skull symmetry}

Some living owls have skulls with asymmetrical otic regions as an adaptation to improve sound localization (3). We qualitatively examined the otic regions in the two best preserved skulls of Shuvuuia (IGM 100/1304 and IGM 100/1001; Fig. S11) to assess where asymmetry was present in late-branching alvarezsauroids. The larger of these skulls, IGM 100/1304, has been taphonomically distorted so that the left side of the braincase is dorsally and slightly posteriorly displaced relative to the right side. This distortion affects each of the braincase bones, i.e., the supraoccipital, exoccipital/opisthotic, prootic, laterosphenoid and basisphenoid, approximately equally. When visually correcting for this distortion we find no evidence of asymmetry. The smaller skull, IGM 100/1001, has a nearly undistorted braincase, but not all of the bones are 


\section{Science \\ MIAAAS}

Submitted Manuscript: Confidential

preserved. Other than differential breakage on the contralateral sides of the braincase, we can find no evidence of asymmetry in IGM100/1001. 


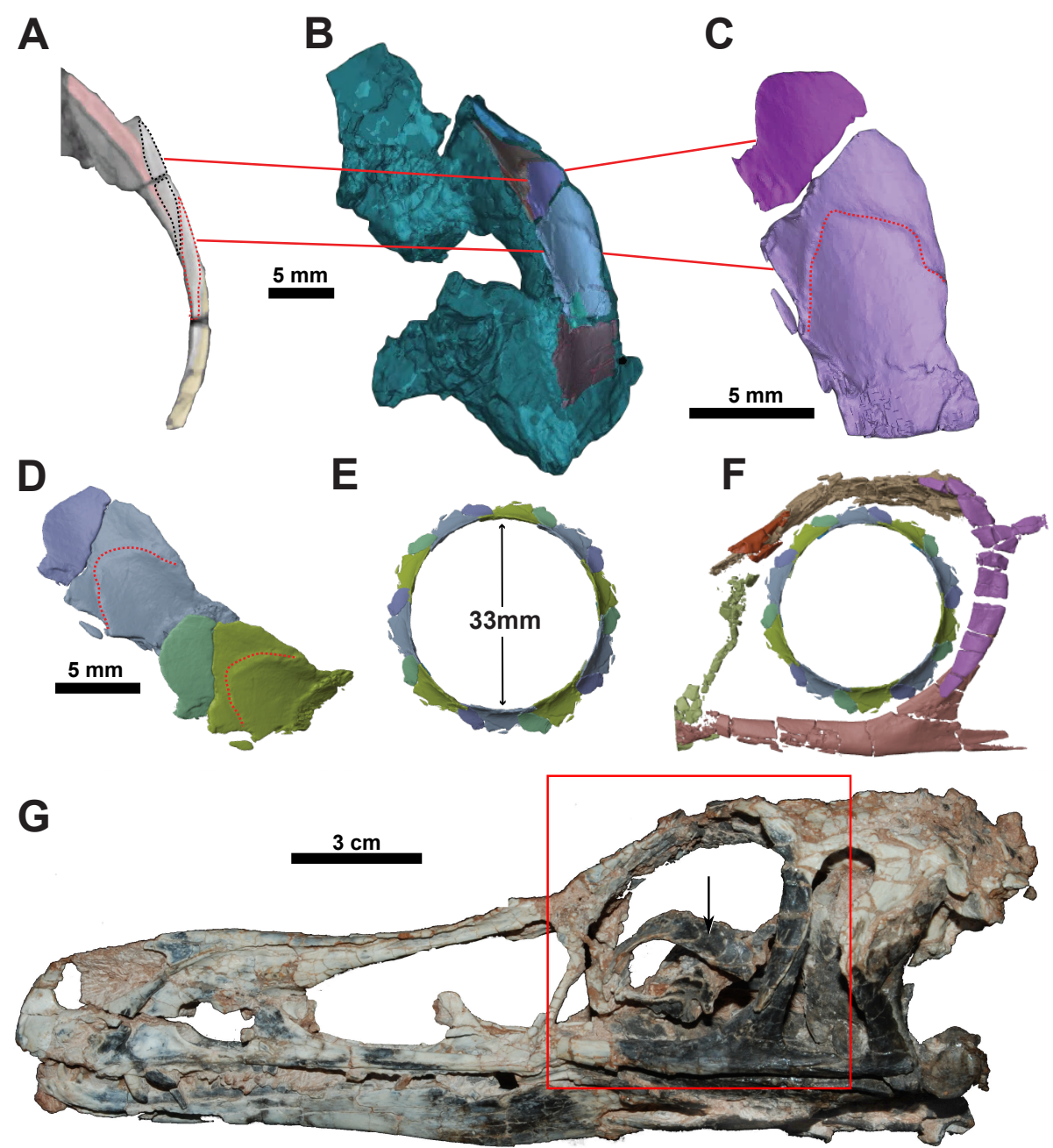

Fig. S1. Reconstruction of the scleral ring of Haplocheirus sollers (IVPP V15988). A, two well-preserved in situ ossicles were identified from the detached matrix of the left orbit (black dashed line $=$ anterior plate, red dashed line $=$ posterior plate). $\mathbf{B}$, These ossicles were segmented in the detached matrix. $\mathbf{C}$, The ossicles were rendered as 3D objects (red dashed line denotes the anterior margin of the posterior plate). D, The gap between the anterior and posterior region of the anterior ossicle was closed and the two-plate element duplicated, with the duplicate placed on the posterodorsal surface of the original element. E, This process was repeated to form a circular ring comprising 20 ossicles, with an internal diameter of $\sim 33 \mathrm{~mm}$. F, The reconstructed scleral ossicle ring positioned inside the segmented left orbit of the holotype. G, skull of Haplocheirus sollers in left lateral view before damage to ring, showing region in $\mathbf{F}$ outlined in red and with arrow indicating dorsal half of the ring. Scale bars for $\mathbf{A}-\mathbf{E}, \mathbf{G}$ as labelled, $\mathbf{F}$ not to scale. 

Science

\IAAAS
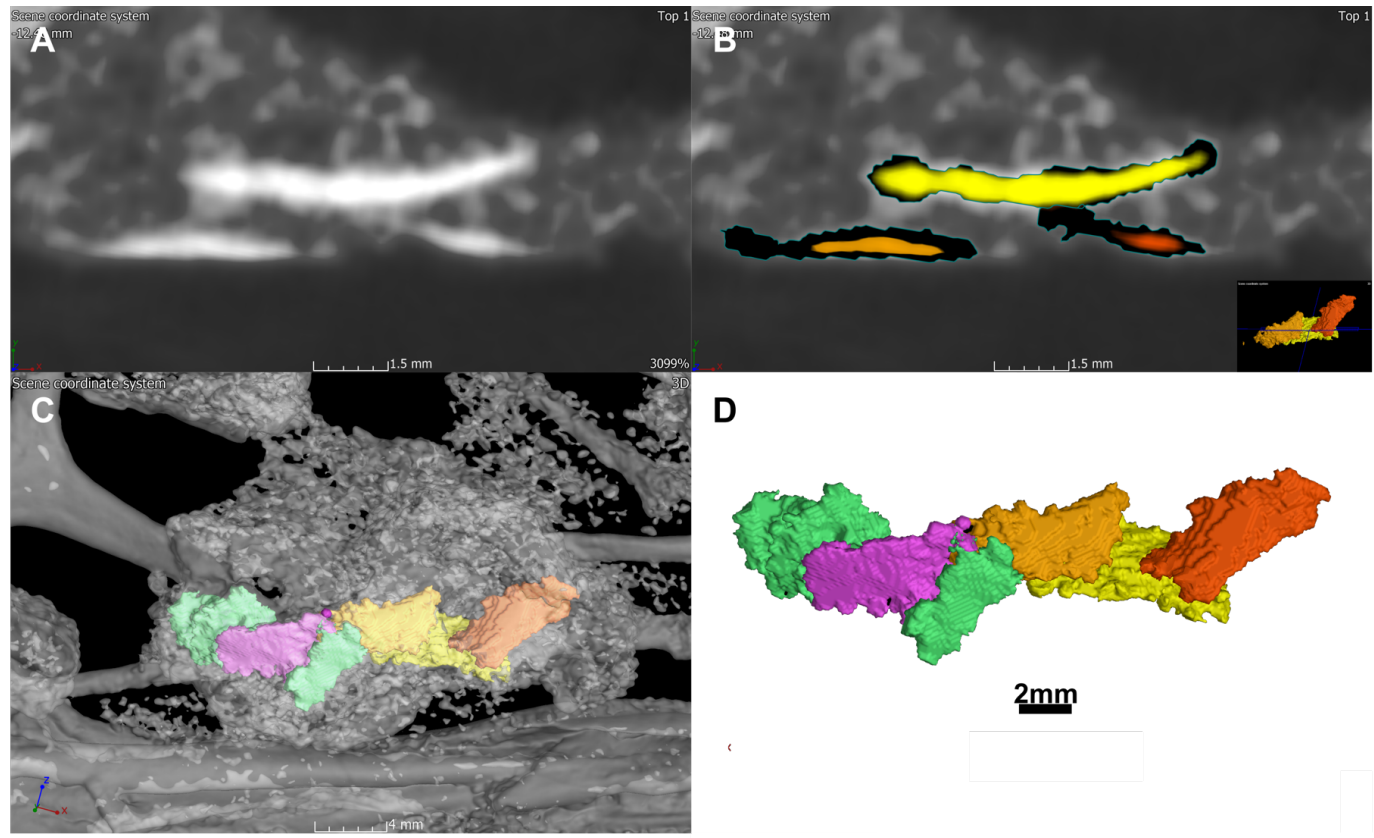

D

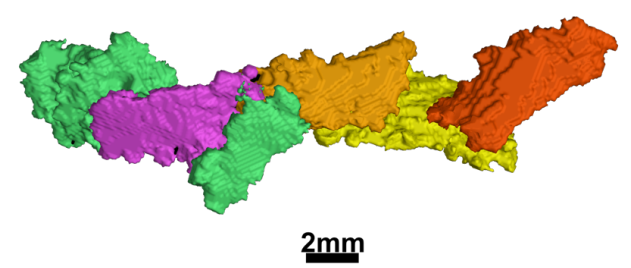

E

$\mathbf{F}$
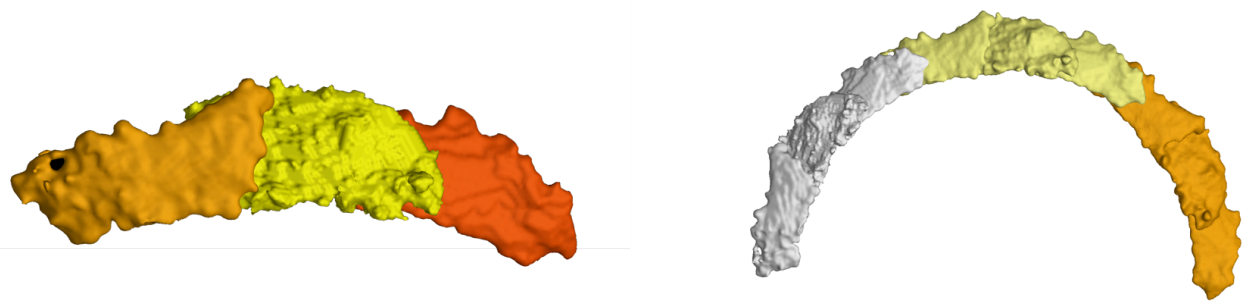

$2 \mathrm{~mm}$

G

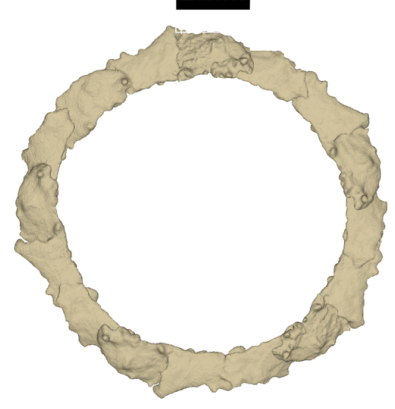

I

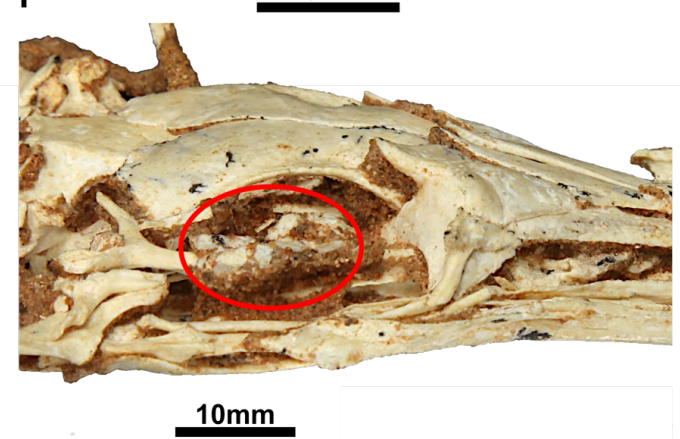

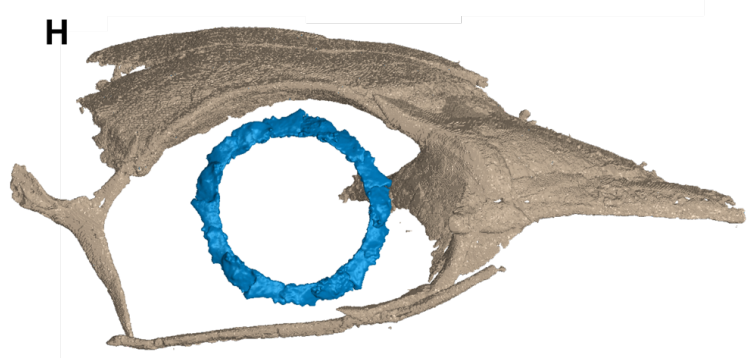

$10 \mathrm{~mm}$

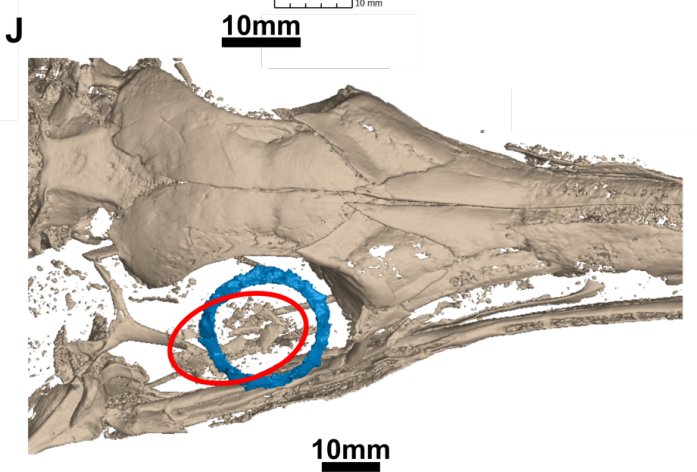


Fig. S2. Reconstruction of the scleral ring of Shuvuuia deserti (IGM 100/0977). A, Wellpreserved ossicles were identified in $\mu \mathrm{CT}$ scan cross-sections. B, Ossicles were segmented using region-growing tool in VG Studio Max. C, Segmented in-situ ossicles showing surrounding matrix. D, Ossicles isolated from matrix and visually inspected. E, The best three ossicles were selected and rotated so that the curvature matched, with $30 \%$ overlap of adjacent ossicles. F, Sections of three ossicles were digitally copied and assembled into a partial ring structure. $\mathbf{G}$, The completely reconstructed ring comprising 19 total ossicles. $\mathbf{H}$, The reconstructed ring in blue inside the reconstructed orbit used to obtain measurements (see Fig. S3 for more details). I, IGM100/0977 in left lateral view (mirrored for display) showing ossicle mass circled in red. J, the reconstructed scleral ring positioned in as-preserved orbit of IGM100/0977, showing ossicle mass circled in red. Scale bars as labelled. 

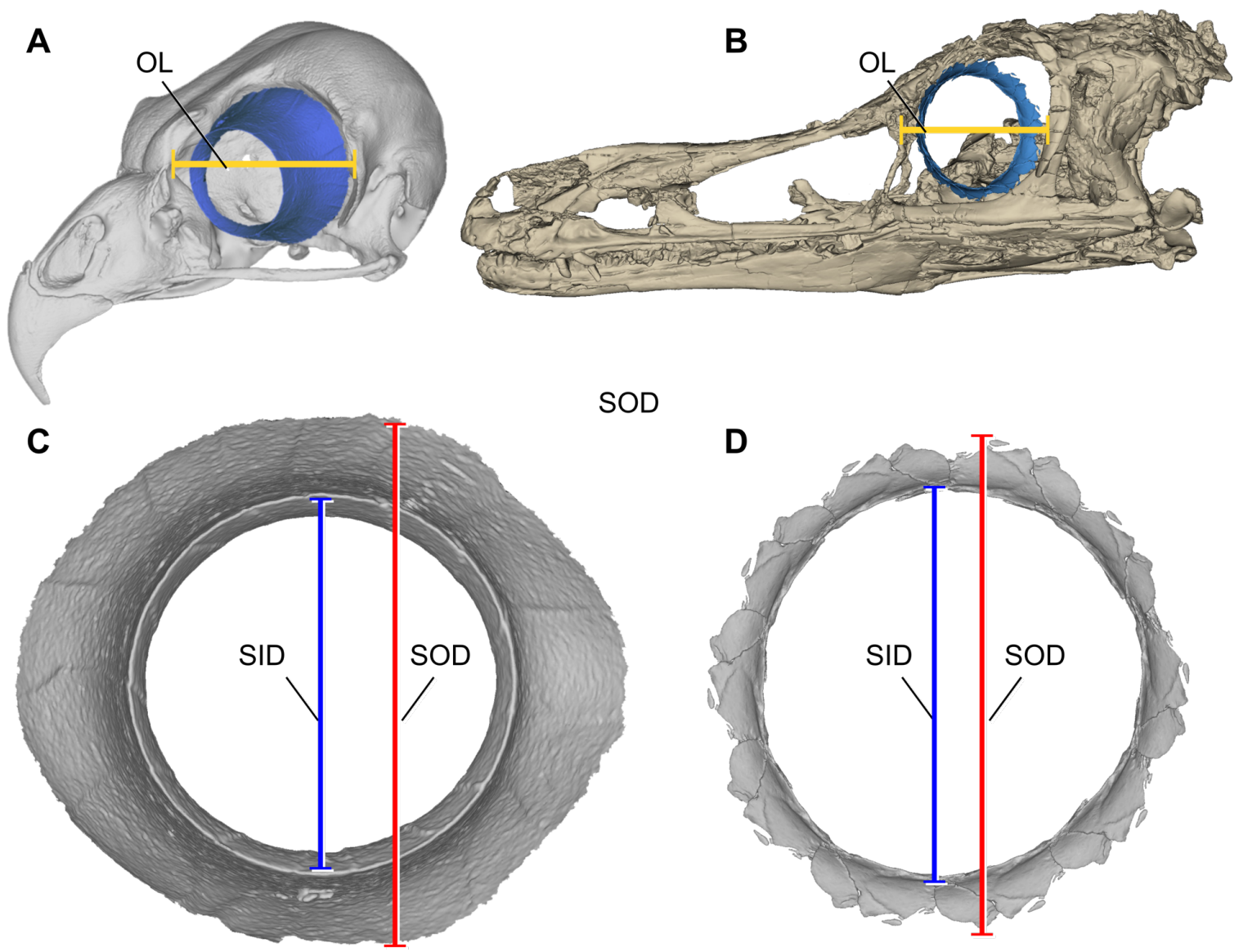

Fig. S3. Orbital measurements used in this study. A, Cranium of Bubo scandiacus (Snowy Owl) in oblique left lateral view, showing scleral ring and orbital length measurement. B, Cranium and mandible of Haplocheirus sollers in left lateral view, showing scleral ring and orbital length measurement. $\mathbf{C}$, Isolated scleral ring of $\mathbf{A}$ in anterior view, showing scleral ring measurements. D, Isolated scleral ring of $\mathbf{B}$ in anterior view, showing scleral ring measurements. Abbreviations: OL: orbital length; SID: scleral ring inner diameter; SOD: scleral ring outer diameter. A, B scaled to orbital length; C, D scaled to SID. 

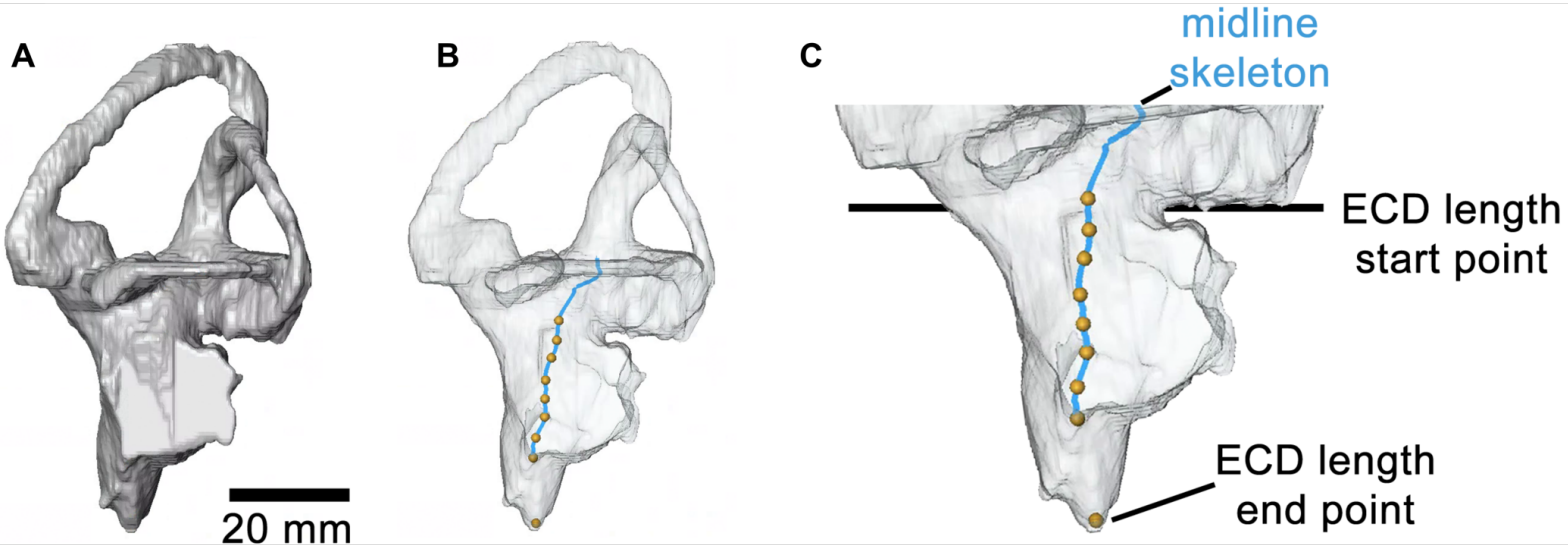

Fig. S4. Skeletonized ECD landmarking method using scaled digital model of the endosseous labyrinth of Velociraptor mongoliensis (IGM 100/976). A, Endosseous labyrinth model prior to skeletonization. B, Semi-transparent endosseous labyrinth model showing midline skeleton of the endosseous cochlear duct and vestibule (blue line). C, Magnification showing landmarks on midline skeleton of the ECD and the ventralmost apex of the duct, initiating dorsally at the narrowest point between the duct and the vestibule. Duct lengths of extant birds and extinct non-avialan theropods were measured as the summed Euclidean distances between these points. Scale bar equals $20 \mathrm{~mm}$. 

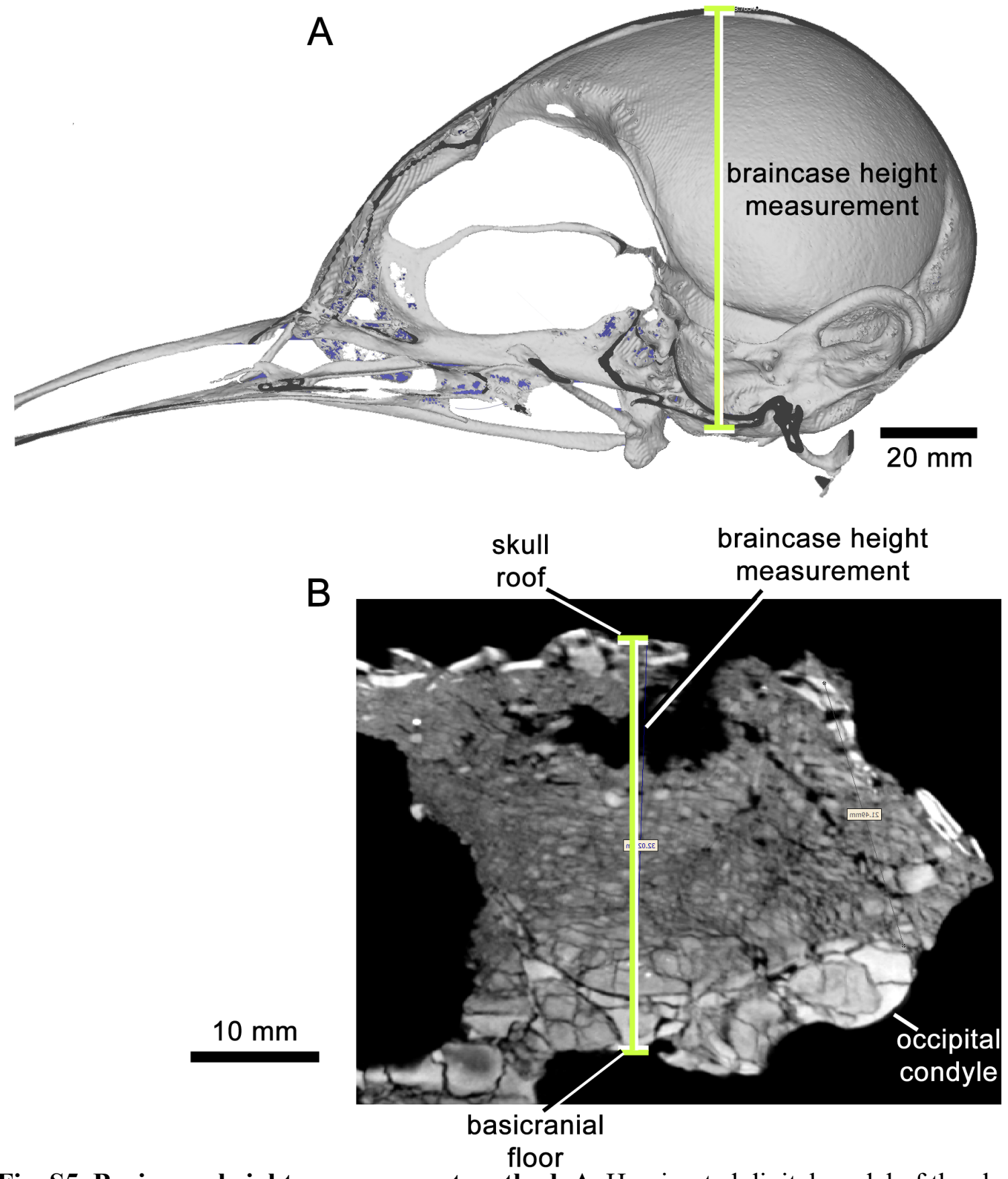

Fig. S5. Braincase height measurement method. A, Hemisected digital model of the skull of Acanthisitta chloris NHMUK 1940.12.8.146 showing braincase height measurement. B, Sagittal midline slice through $\mu \mathrm{CT}$ data for the skull of Haplocheirus sollers (IVPP V15988) showing the braincase height measurement. Braincase height was measured as the maximum vertical distance between the basicranial floor and the skull roof. Scale bars as labelled. 


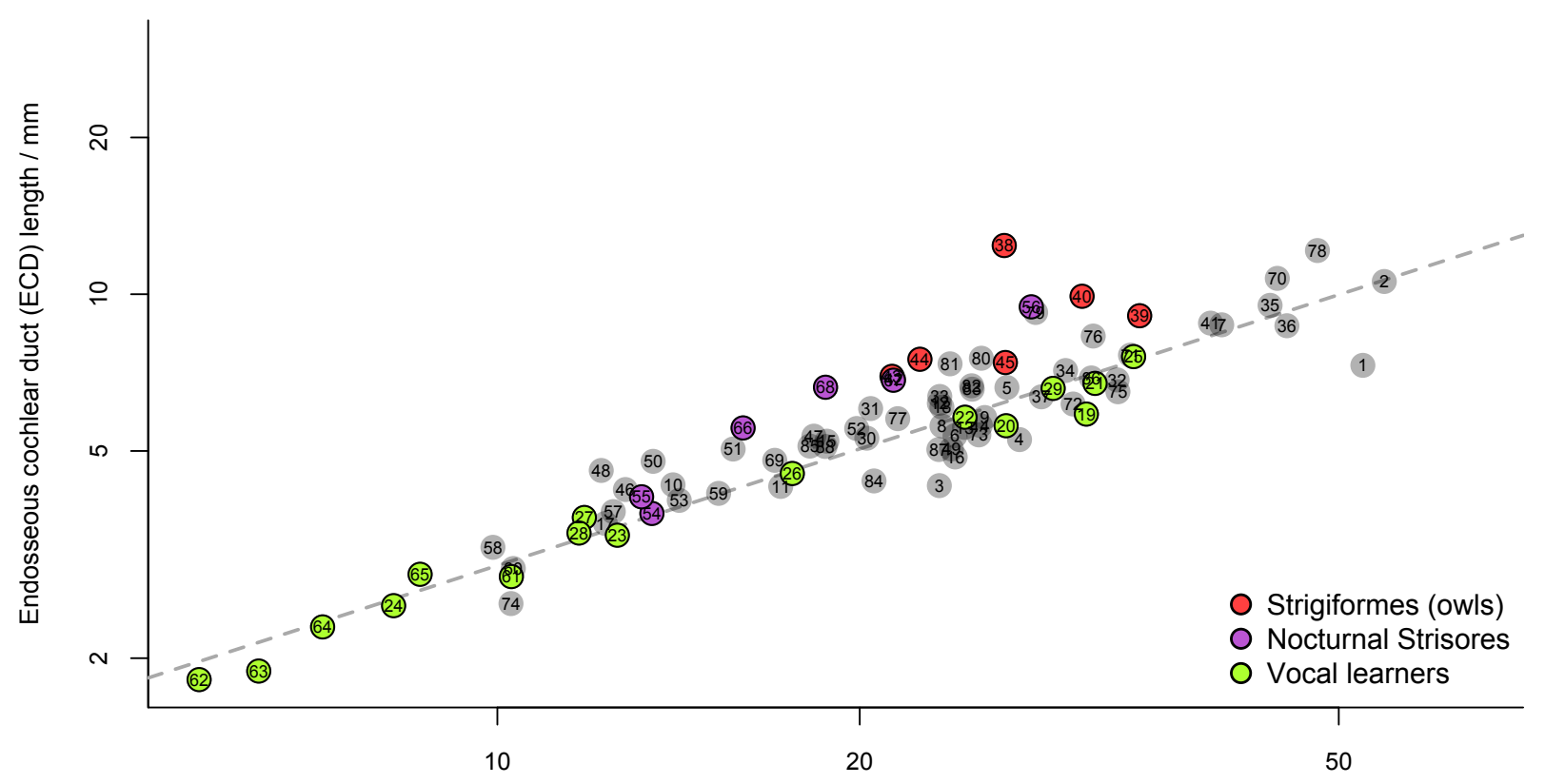

Braincase height / $\mathrm{mm}$

Fig. S6. Endosseous cochlear duct (ECD) length versus braincase height in extant birds. Vocal learners (hummingbirds, parrots, oscine passerines) show no co-ordinated deviation from the regression line for ECD length $\sim$ braincase height (dashed line; coefficients in Table S1). Number key: 1, Struthio camelus; 2, Casuarius casuarius; 3, Apteryx australis; 4, Apteryx haastii; 5, Tachyeres brachypterus; 6, Aythya fuligula; 7, Cygnus olor; 8, Gallus gallus; 9, Phasianus colchicus; 10, Coturnix coturnix; 11, Gelochelidon nilotica; 12, Hydroprogne caspia; 13, Larus argentatus; 14, Creagrus furcatus; 15, Alca torda; 16, Scolopax rusticola; 17, Actitis hypoleucos; 18, Haematopus ostralegus; 19, Strigops habroptila; 20, Nestor notabilis; 21, Ara macao; 22, Psittacus erithacus; 23, Melopsittacus undulatus; 24, Acanthorhynchus superciliosus; 25, Corvus corax; 26, Dicrurus paradiseus; 27, Luscinia megarhynchos; 28, Passer domesticus; 29, Menura novaehollandiae; 30, Falco tinnunculus; 31, Falco subbuteo; 32, Pandion haliaetus; 33, Circus cyaneus; 34, Buteo buteo; 35, Aquila chrysaetos; 36, Vultur gryphus; 37, Cathartes sp.; 38, Tyto alba; 39, Pulsatrix perspicillata; 40, Strix aluco; 41, Bubo scandiacus; 42, Megascops kennicottii; 43, Otus spilocephalus; 44, Athene noctua; 45, Surnia ulula; 46, Trogon curucui; 47, Coracias garrulus; 48, Alcedo atthis; 49, Ramphastos dicolorus; 50, Sphyrapicus varius; 51, Dendrocopos major; 52, Picus viridis; 53, Eurostopodus mystacalis; 54, Chordeiles minor; 55, Caprimulgus macrurus; 56, Podargus strigoides; 57, Apus apus; 58, Chaetura brachyura; 59, Streptoprocne zonaris; 60, Hemiprocne comata; 61, Patagona gigas; 62, Archilochus colubris; 63, Selasphorus rufus; 64, Colibri coruscans; 65, Topaza pyra; 66, Aegotheles cristatus; 67, Steatornis caripensis; 68, Nyctibius griseus; 69, Cuculus canorus; 70, Diomedea exulans; 71, Phoebastria nigripes; 72, Phoebastria immutabilis; 73, Fulmarus glacialis; 74, Pelagodroma marina; 75, Ciconia nigra; 76, Ciconia ciconia; 77, Ardea cinerea; 78, Balaeniceps rex; 79, Morus bassanus; 80, Phalacrocorax auritus; 81, Phalacrocorax carbo; 82, Phalacrocorax harrisi; 83, Fregata magnificens; 84, Phaethon lepturus; 85, Podiceps cristatus; 86, Phoenicopterus ruber; 87, Opisthocomus hoazin; 88, Columba livia. 


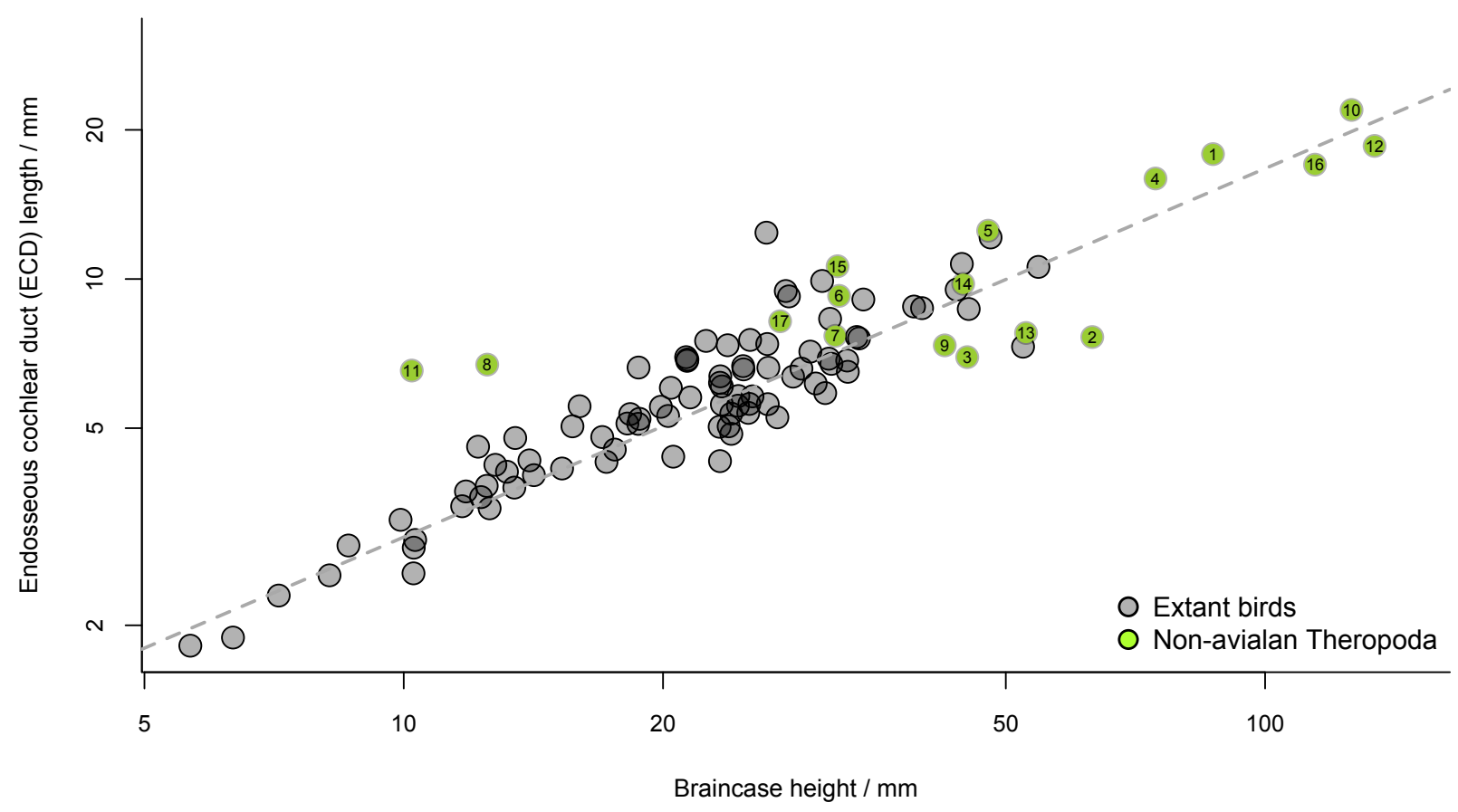

Fig. S7. Endosseous cochlear duct (ECD) length versus braincase height in extant birds and extinct non-avialan theropods. Dashed line is the regression line for ECD length $\sim$ braincase height (coefficients in Table S1). Number key: 1, Alioramus altai, Tyrannosauroidea, IGM 100/1844; 2, Citipati osmolskae, Oviraptorosauria, IGM 100/978; 3, Conchoraptor gracilis, Oviraptorosauria, IGM 100/3006; 4, Dromaeosaurus albertensis, Dromaeosauridae, AMNH FARB 5356; 5, Erlikosaurus andrewsi, Therizinosauria, IGM 100/111; 6, Haplocheirus sollers, Alvarezsauroidae, IVPP V15988; 7, Incisivosaurus gauthieri, Oviraptorosauria, IVPP_V13326; 8, Troodontidae sp. IGM 100/1126; 9, Khaan mckennai, Oviraptorosauria, IGM 100/973; 10, Murusraptor barrosaensis, Megaraptora, MCF-PVPH 411; 11, Shuvuuia deserti, Alvarezsauroidea, IGM 100/1304; 12, Sinraptor dongi, Allosauroidea, IVPP V10600; 13, Struthiomimus altus, Ornithomimosauria, AMNH 5355; 14, Tsaagan mangas, Dromaeosauridae, IGM 100/1015; 15, Velociraptor mongoliensis, Dromaeosauridae, IGM 100/976; 16, Viavenator exxoni, Abelisauridae,_MAU-Pv-LI-530; 17, Xiyunykus pengi, Alvarezsauroidea, IVPP V22783. For identifications of extant birds use Fig. S6. 


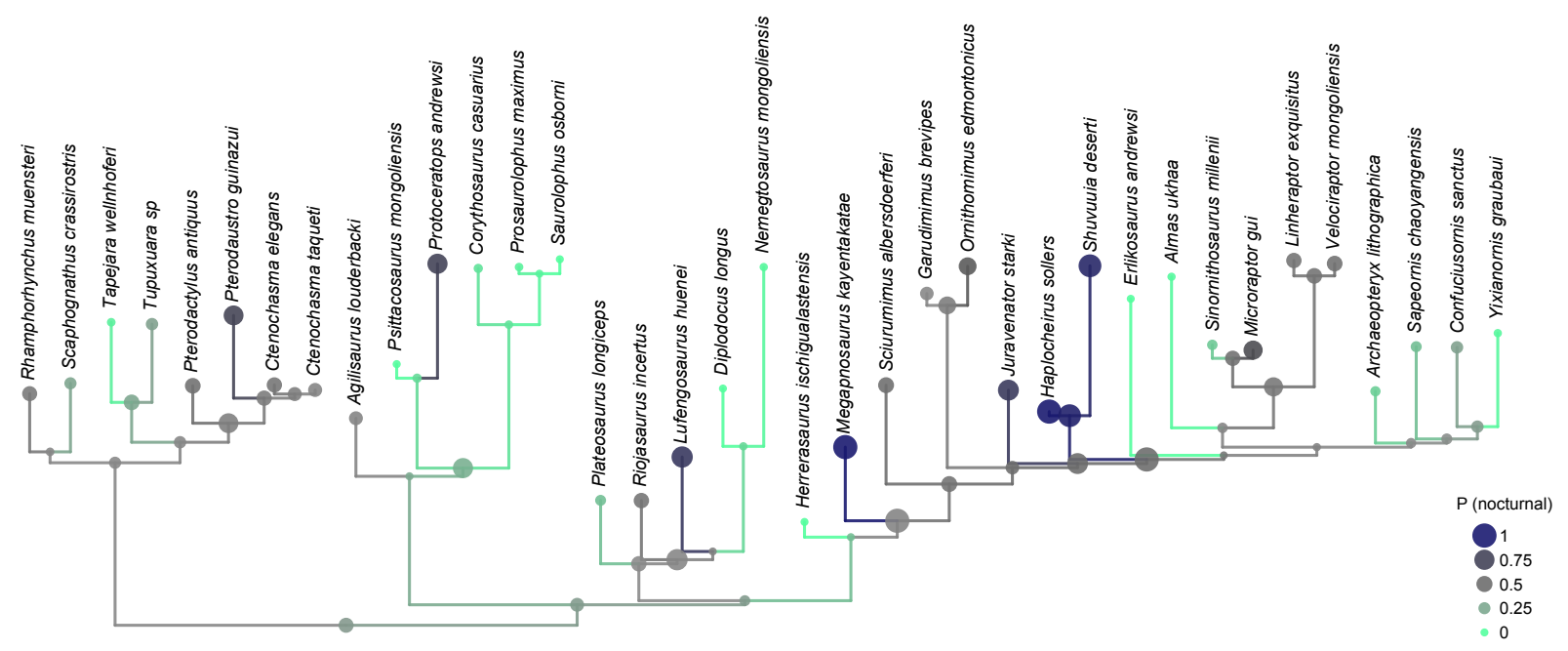

Fig. S8. Timescaled tree of Mesozoic theropod and ornithodiran relationships showing posterior probabilities of nocturnal vision capability based on SOR measurements and pDFA analysis (see methods). Circles represent terminal taxa and ancestral state reconstructions and are colored according to pp nocturnal values (see Table S1 and main text Fig. 4). Phylogeny is modified from Benson et al (34) and represents a consensus view of ornithodiran interrelationships. Image was prepared using functions from the R 4.0.0 (45) package ape version 5.0 (46), including the function ace() for ancestral state estimation. 


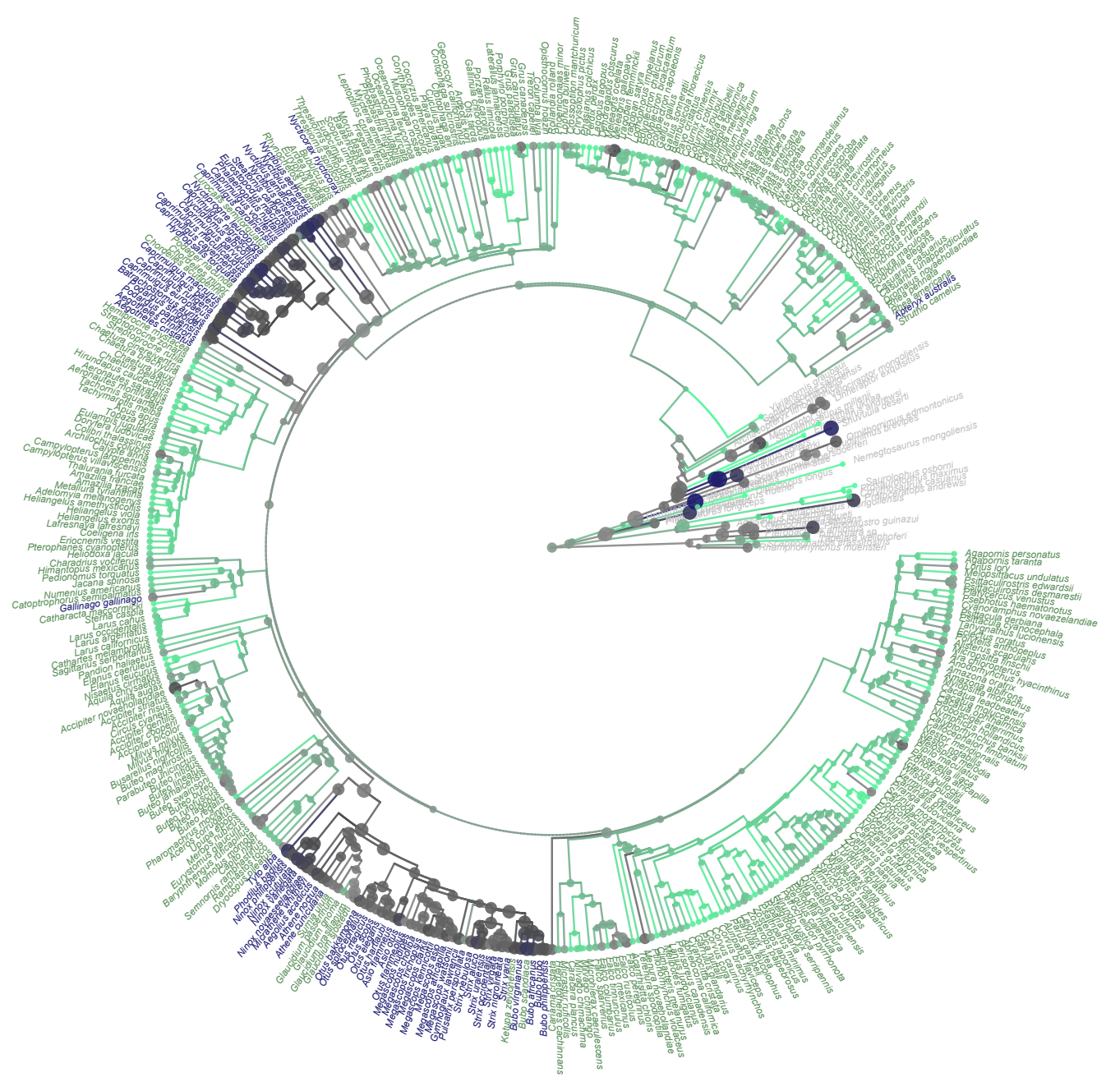

Fig. S9. Timescaled tree of theropod relationships in this study showing posterior probabilities of nocturnal vision capability based on scleral ring measurements and pDFA analysis (see Methods). Circles represent terminal taxa and ancestral state reconstructions and are colored according to pp nocturnal values (see Table S1 and main text Fig. 4). Phylogeny represents one topology from (32) (described in supplementary text). Image was prepared using functions from the R 4.0.0 (45) package ape version 5.0 (46), including the function ace() for ancestral state estimation. 


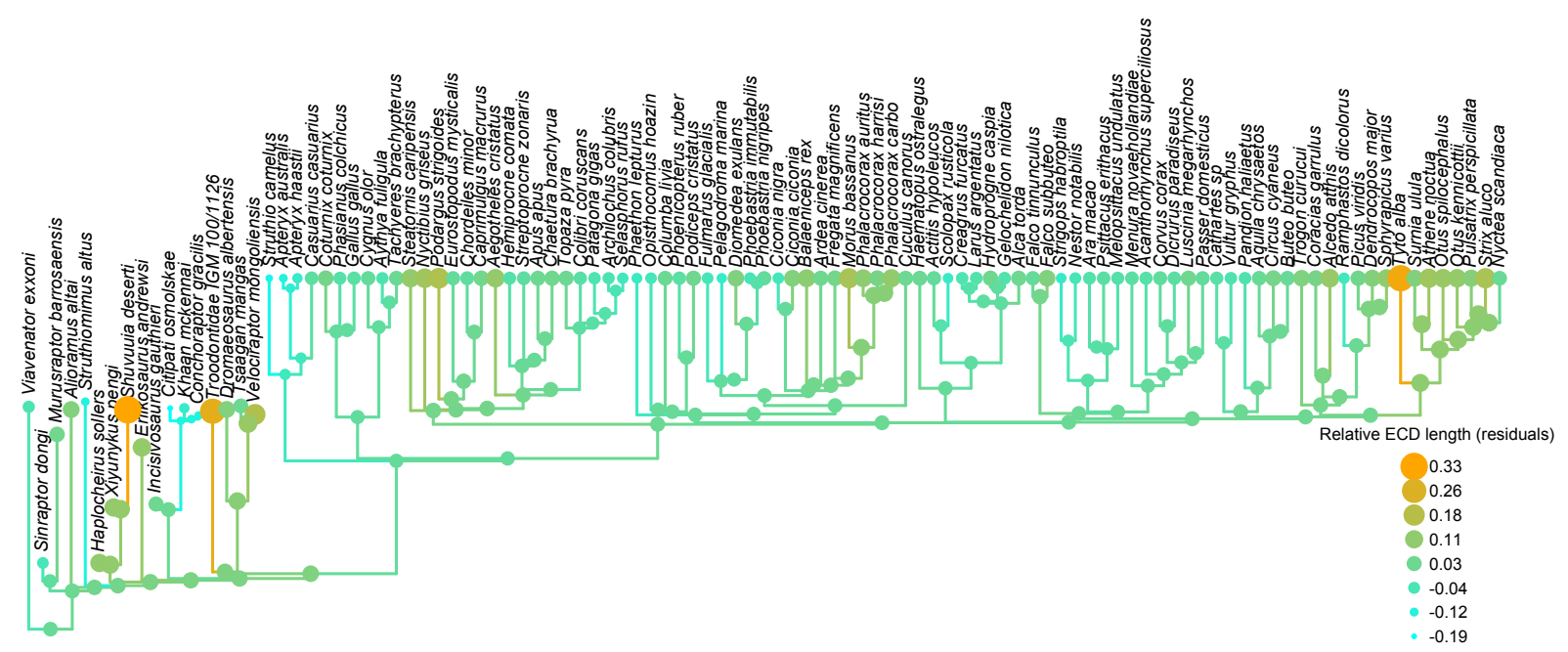

Fig. S10. Timescaled tree of theropod relationships, including extant avialans showing relative lengths of the endosseous cochlear duct (residuals from phylogenetic regression of duct length on braincase height). Filled circles represent terminal taxa and ancestral state reconstructions and are colored according to relative duct length (see Table 2 and main text Fig. 3 ). Phylogeny represents one configuration of our composite tree (described in Methods). Image was prepared using functions from the R 4.0.0 (45) package ape version 5.0 (46), including the function ace() for ancestral state estimation. 
A

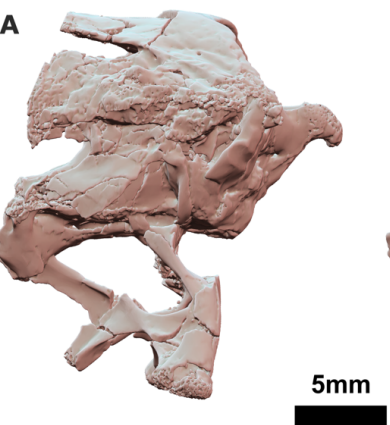

B

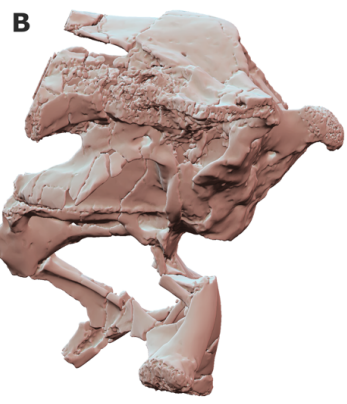

$\mathbf{F}$

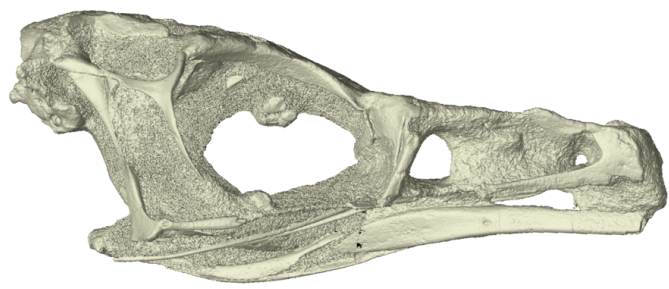

G

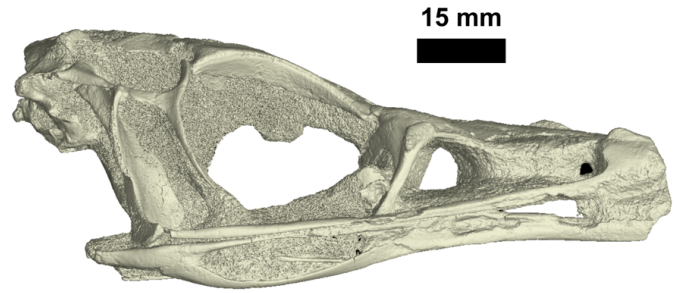

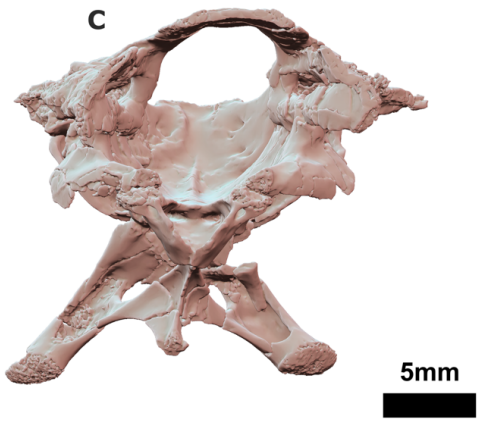

D

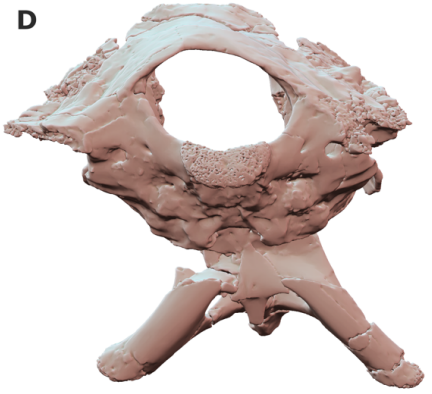

E

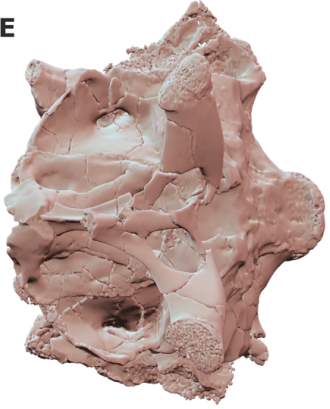

$5 \mathrm{~mm}$

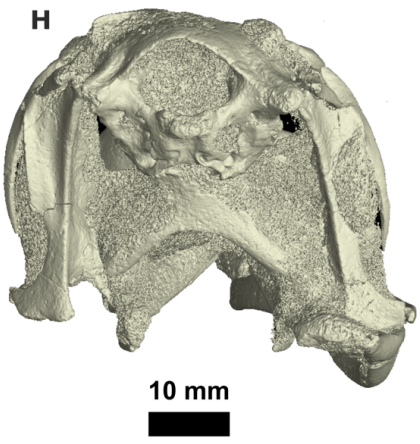

I

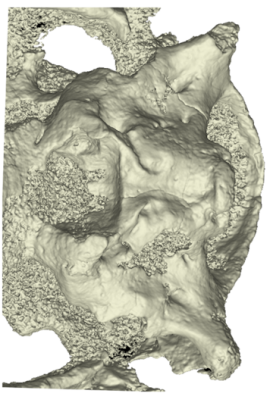

$10 \mathrm{~mm}$

Fig. S11. Images of Shuvuuia deserti used to evaluate skull symmetry. A-E, braincase of Shuvuuia deserti IGM100/1304 in: A, left lateral; B, right lateral (mirrored); C, anterior; D, posterior; E, ventral views. F-I, skull of Shuvuuia deserti IGM100/1001 in: F, left lateral (mirrored); G, right lateral; H, posterior; I, ventral views. Scale bars as labelled. 
MIAAAS

Taxon

Mean pp nocturnal

Min pp nocturnal

Max pp pocturnal

Rhamphorhynchus_muensteri

0.4491

Scaphognathus_crassirostris

0.2654

0.4156

0.4737

Tapejara_wellnhoferi

0.0444

0.2535

0.2786

Tupuxuara_sp

0.287

0.0376

0.0524

Pterodactylus_antiquus

0.4778

0.2657

0.3082

Pterodaustro_guinazui

0.7196

0.4478

0.4962

Ctenochasma_elegans

0.4674

0.6563

0.7646

Ctenochasma_taqueti

0.3868

0.4404

0.4965

Agilisaurus_louderbacki

0.3541

0.3629

0.4049

Psittacosaurus_mongoliensis

0.0058

0.2939

0.3979

Protoceratops_andrewsi

0.7557

0.0035

0.0094

Corythosaurus_casuarius

0.0887

0.7228

0.786

Prosaurolophus_maximus

0.0395

0.0604

0.1325

Saurolophus_osborni

0.0017

0.0311

0.0523

Plateosaurus_longiceps

0.1919

0.001

0.0031

Riojasaurus_incertus

0.4853

0.159

0.2347

Lufengosaurus_huenei

0.8097

0.4175

0.5532

Diplodocus_longus

0.0019

0.7678

0.8365

Nemegtosaurus_mongoliensis

0.023

0.001

0.0032

Herrerasaurus_ischigualastensis

0.0011

0.0152

0.0369

Megapnosaurus_kayentakatae

0.9989

0.0005

0.0019

Sciurumimus_albersdoerferi

0.4908

0.9979

0.9995

Garudimimus_brevipes

0.3641

0.4692

0.5109

Ornithomimus_edmontonicus

0.6218

0.3369

0.3896

Juravenator_starki

0.7973

0.5961

0.6385

Haplocheirus_sollers

0.9987

0.7562

0.8239

0.9134

0.998

0.999

Shuvuuia_deserti

0.0002

0.8967

0.9208

Erlikosaurus_andrewsi

0.0178

0.0002

0.0004

Almas_ukhaa

0.4079

0.0158

0.0204

Sinornithosaurus_millenii

0.4479

0.1532

0.7122

Microraptor_gui

0.1475

0.7184

Velociraptor_mongoliensis

0.4769

0.4484

0.5004

Linheraptor_exquisitus

0.4745

0.4464

0.502

Archaeopteryx_lithographica

0.1391

0.1245

0.1511

Sapeornis_chaoyangensis

0.1813

0.1502

0.2113

Confuciusornis_sanctus

0.2726

0.2553

0.2863

Yixianornis_graubaui

0.0187

0.0174

0.0204 
Table S1. Posterior probability of nocturnality for extinct theropods averaged over our phylogenetic flexible discriminant analyses 1-6 (see Methods; each analysis is averaged over 50 trees). Analysis 5 yields the most accurate classification. 


\begin{tabular}{|c|c|c|c|c|c|c|c|c|c|}
\hline Model & $\mathbf{N}$ & AICc & $\mathbf{R 2}$ & $\lambda$ & Variable & Coefficient & Std.Error & p value & notes \\
\hline \multirow[t]{2}{*}{$\begin{array}{l}\text { ECD.length } \sim \\
\text { braincase.height }\end{array}$} & 88 & -226.2 & 0.776 & 0.89 & intercept & -0.265 & 0.065 & $<0.0001$ & $\begin{array}{l}\text { decisively } \\
\text { best model }\end{array}$ \\
\hline & & & & & braincase.height & 0.744 & 0.041 & $<0.0001$ & \\
\hline \multirow{2}{*}{$\begin{array}{l}\text { ECD.length } \\
\text { hindbrain.height }\end{array}$} & 88 & -211.0 & 0.733 & 0.89 & intercept & -0.124 & 0.064 & 0.0581 & \\
\hline & & & & & hindbrain.height & 0.700 & 0.043 & $<0.0001$ & \\
\hline \multirow{2}{*}{$\begin{array}{l}\text { ECD.length } \sim \\
\text { braincase.width }\end{array}$} & 88 & -220.2 & 0.76 & 0.84 & intercept & -0.254 & 0.065 & 0.0002 & \\
\hline & & & & & braincase.width & 0.704 & 0.04 & $<0.0001$ & \\
\hline \multirow{2}{*}{$\begin{array}{l}\text { ECD.length } \\
\text { body.mass }\end{array}$} & 88 & -178.7 & 0.615 & 0.92 & intercept & 0.262 & 0.057 & 0.0001 & \\
\hline & & & & & body.mass & 0.167 & 0.013 & $<0.0001$ & \\
\hline \multirow[t]{2}{*}{$\begin{array}{l}\text { ECD.length } \sim \\
\text { braincase.height }\end{array}$} & 71 & -172.9 & 0.756 & 0.91 & intercept & & 0.073 & & $\begin{array}{l}\text { decisively } \\
\text { best model }\end{array}$ \\
\hline & & & & & braincase.height & 0.729 & 0.047 & $<0.0001$ & \\
\hline \multirow{2}{*}{$\begin{array}{l}\text { ECD.length } \\
\text { hindbrain.height }\end{array}$} & 71 & -159.2 & 0.705 & 0.89 & intercept & -0.096 & 0.072 & 0.1878 & \\
\hline & & & & & hindbrain.height & 0.678 & 0.049 & $<0.0001$ & \\
\hline \multirow{2}{*}{$\begin{array}{l}\text { ECD.length } \\
\text { braincase.width }\end{array}$} & 71 & -163.5 & 0.722 & 0.84 & intercept & -0.218 & 0.075 & 0.0051 & \\
\hline & & & & & braincase.width & 0.679 & 0.047 & $<0.0001$ & \\
\hline \multirow{2}{*}{$\begin{array}{l}\text { ECD.length } ~ \\
\text { postrostral.length }\end{array}$} & 71 & -146.1 & 0.645 & 0.91 & intercept & -0.136 & 0.086 & 0.1190 & \\
\hline & & & & & postrostral.length & 0.592 & 0.05 & $<0.0001$ & \\
\hline \multirow{2}{*}{$\begin{array}{l}\text { ECD.length } \\
\text { body.mass }\end{array}$} & 71 & -135.3 & 0.587 & 0.93 & intercept & 0.288 & 0.06 & $<0.0001$ & \\
\hline & & & & & body.mass & 0.160 & 0.015 & $<0.0001$ & \\
\hline
\end{tabular}

Table S2. Phylogenetic regression model comparison of scaling variables related to endosseous cochlear duct (ECD) length in extant birds. Upper model set includes $\mathrm{N}=88$ species for which ECD length, braincase height, hindbrain height, braincase width and body mass were available. Lower model set includes $\mathrm{N}=71$ species for which postrostral skull length was also available. $\mathrm{N}$ is the sample size of extant bird species analyzed. AICc is Akaike's information criterion for finite sample sizes and indicates decisive support for the model ECD length $\sim$ braincase height at both sample sizes. Lambda $(\lambda)$ is a phylogenetic signal parameter (42). $\mathrm{R}^{2}$ is computed by comparison to an intercept-only null model following the procedure of (47). All variables were $\log _{10}$-transformed prior to analysis. Results represent the mean values from analyses conducted across 100 trees from the distribution of Jetz et al. (32), based on the Hackett (31) backbone. 


\begin{tabular}{|c|c|c|c|c|}
\hline Species & Group & Common name & $\begin{array}{l}\text { Residual } \\
\text { ECD } \\
\text { length }\end{array}$ & Elongation (qualitative) \\
\hline Shuvuuia deserti & Alvarezsauroidea & (fossil species) & 0.329 & high elongation \\
\hline Tyto alba & Strigiformes (owls) & barn owl & 0.301 & high elongation \\
\hline $\begin{array}{l}\text { Troodontidae IGM } \\
100 / 1126\end{array}$ & Troodontidae & (fossil species) & 0.276 & high elongation \\
\hline Velociraptor mongoliensis & Dromaeosauridae & (fossil species) & 0.172 & moderate elongation \\
\hline Podargus strigoides & Strisores (nightbirds) - nocturnal & tawny frogmouth & 0.167 & moderate elongation \\
\hline Strix aluco & Strigiformes (owls) & tawny owl & 0.156 & moderate elongation \\
\hline Morus bassanus & Aequorlitornithes (water birds) & northern gannet & 0.153 & moderate elongation \\
\hline Nyctibius griseus & Strisores (nightbirds) - nocturnal & common potoo & 0.140 & moderate elongation \\
\hline Athene noctua & Strigiformes (owls) & little owl & 0.135 & moderate elongation \\
\hline Otus spilocephalus & Strigiformes (owls) & mountain scops owl & 0.119 & moderate elongation \\
\hline Alcedo atthis & Coraciimorphae & common kingfisher & 0.118 & moderate elongation \\
\hline Erlikosaurus andrewsi & Therizinosauria & (fossil species) & 0.114 & moderate elongation \\
\hline Megascops kennicottii & Strigiformes (owls) & western screech owl & 0.114 & moderate elongation \\
\hline Aegotheles cristatus & Strisores (nightbirds) - nocturnal & Australian owlet-nightjar & 0.112 & moderate elongation \\
\hline Steatornis caripensis & Strisores (nightbirds) - nocturnal & oilbird & 0.111 & moderate elongation \\
\hline Haplocheirus sollers & Alvarezsauroidea & (fossil species) & 0.111 & moderate elongation \\
\hline Xiyunykus pengi & Alvarezsauroidea & (fossil species) & 0.111 & moderate elongation \\
\hline Phalacrocorax carbo & Aequorlitornithes (water birds) & great cormorant & 0.108 & moderate elongation \\
\hline Sphyrapicus varius & Coraciimorphae & $\begin{array}{l}\text { yellow-bellied sapsucker } \\
\text { (woodpecker) }\end{array}$ & 0.104 & moderate elongation \\
\hline Phalacrocorax auritus & Aequorlitornithes (water birds) & $\begin{array}{l}\text { double-crested } \\
\text { cormorant }\end{array}$ & 0.099 & moderate elongation \\
\hline Balaeniceps rex & Aequorlitornithes (water birds) & shoebill & 0.098 & moderate elongation \\
\hline Pulsatrix perspicillata & Strigiformes (owls) & spectacled owl & 0.083 & moderate elongation \\
\hline Dendrocopos major & Coraciimorphae & $\begin{array}{l}\text { great spotted } \\
\text { woodpecker }\end{array}$ & 0.078 & moderate elongation \\
\hline Surnia ulula & Strigiformes (owls) & northern hawk owl & 0.076 & moderate elongation \\
\hline $\begin{array}{l}\text { Dromaeosaurus } \\
\text { albertensis }\end{array}$ & Dromaeosauridae & (fossil species) & 0.075 & moderate elongation \\
\hline Alioramus altai & Tyrannosauroidea & (fossil species) & 0.074 & moderate elongation \\
\hline Ciconia ciconia & Aequorlitornithes (water birds) & white stork & 0.072 & limited elongation \\
\hline Falco subbuteo & Falconiformes & Eurasian hobby & 0.071 & limited elongation \\
\hline Diomedea exulans & Aequorlitornithes (water birds) & wandering albatross & 0.069 & limited elongation \\
\hline Trogon curucui & Coraciimorphae & blue-crowned trogon & 0.067 & limited elongation \\
\hline Coracias garrulus & Coraciimorphae & european roller & 0.053 & limited elongation \\
\hline Phalacrocorax harrisi & Aequorlitornithes (water birds) & flightless cormorant & 0.052 & limited elongation \\
\hline Circus cyaneus & Accipitriformes & hen harrier & 0.051 & limited elongation \\
\hline Coturnix coturnix & Galliformes & common quail & 0.046 & limited elongation \\
\hline Fregata magnificens & Aequorlitornithes (water birds) & magnificent frigate bird & 0.045 & limited elongation \\
\hline Murusraptor barrosaensis & Megaraptoridae & (fossil species) & 0.044 & limited elongation \\
\hline Caprimulgus macrurus & Strisores (nightbirds) - nocturnal & large-tailed nightjar & 0.043 & limited elongation \\
\hline
\end{tabular}


MAAAS

\begin{tabular}{|c|c|c|c|c|}
\hline Picus viridis & Coraciimorphae & $\begin{array}{l}\text { European green } \\
\text { woodpecker }\end{array}$ & 0.041 & limited elongation \\
\hline Luscinia megarhynchos & Passerines & common nightingale & 0.038 & limited elongation \\
\hline Sterna caspia & Aequorlitornithes (water birds) & Caspian tern & 0.038 & limited elongation \\
\hline Chaetura brachyura & Strisores - swift & short-tailed swift & 0.038 & limited elongation \\
\hline Podiceps cristatus & Aequorlitornithes (water birds) & great crested grebe & 0.036 & limited elongation \\
\hline Alca torda & Aequorlitornithes (water birds) & razorbill & 0.035 & limited elongation \\
\hline Ardea cinerea & Aequorlitornithes (water birds) & grey heron & 0.035 & limited elongation \\
\hline Incisivosaurus gauthieri & Oviraptorosauria & (fossil species) & 0.034 & limited elongation \\
\hline Apus apus & Strisores - swift & common swift & 0.032 & limited elongation \\
\hline Topaza pyra & Strisores - hummingbird & $\begin{array}{l}\text { fiery topaz } \\
\text { (hummingbird) }\end{array}$ & 0.031 & limited elongation \\
\hline Cuculus canorus & Otidimorpha & common cuckoo & 0.031 & limited elongation \\
\hline Haematopus ostralegus & Aequorlitornithes (water birds) & Eurasian oystercatcher & 0.029 & limited elongation \\
\hline Tsaagan mangas & Dromaeosauridae & (fossil species) & 0.028 & limited elongation \\
\hline Tachyeres brachypterus & Anseriformes & Falkland steamer duck & 0.027 & limited elongation \\
\hline Columba livia & Columbimorpha & rock dove & 0.026 & limited elongation \\
\hline Bubo scandiacus & Strigiformes (owls) & snowy owl & 0.025 & limited elongation \\
\hline Buteo buteo & Accipitriformes & common buzzard & 0.023 & limited elongation \\
\hline Aquila chrysaetos & Accipitriformes & golden eagle & 0.022 & limited elongation \\
\hline Falco tinnunculus & Falconiformes & common kestrel & 0.016 & limited elongation \\
\hline Cygnus olor & Anseriformes & mute swan & 0.015 & limited elongation \\
\hline Actitis hypoleucos & Aequorlitornithes (water birds) & common sandpiper & 0.014 & limited elongation \\
\hline Phoebastria nigripes & Aequorlitornithes (water birds) & black-footed albatross & 0.013 & limited elongation \\
\hline Eurostopodus mystacalis & Strisores (nightbirds) - nocturnal & white-throated nightjar & 0.013 & limited elongation \\
\hline Passer domesticus & Passerines & house sparrow & 0.012 & limited elongation \\
\hline Corvus corax & Passerines & common raven & 0.008 & limited elongation \\
\hline Chordeiles minor & Strisores (nightbirds) - nocturnal & common nighthawk & 0.004 & limited elongation \\
\hline Streptoprocne zonaris & Strisores - swift & white-collared swift & 0.002 & limited elongation \\
\hline Casuarius casuarius & Palaeognathae & southern cassowary & -0.003 & short \\
\hline Menura novaehollandiae & Passerines & superb lyrebird & -0.003 & short \\
\hline Psittacus erithacus & Psittaciformes & African grey parrot & -0.004 & short \\
\hline Dicrurus paradiseus & Passerines & $\begin{array}{l}\text { greater racket-tailed } \\
\text { drongo }\end{array}$ & -0.006 & short \\
\hline Gallus gallus & Galliformes & red junglefowl & -0.007 & short \\
\hline Phoenicopterus ruber & Aequorlitornithes (water birds) & American flamingo & -0.007 & short \\
\hline Colibri coruscans & Strisores - hummingbird & $\begin{array}{l}\text { sparkling violetear } \\
\text { (hummingbird) }\end{array}$ & -0.010 & short \\
\hline Cathartes sp & Accipitriformes & New World vulture & -0.012 & short \\
\hline $\begin{array}{l}\text { Acanthorhynchus } \\
\text { superciliosus }\end{array}$ & Passerines & western spinebill & -0.013 & short \\
\hline Hemiprocne comata & Strisores - swift & whiskered treeswift & -0.016 & short \\
\hline Melopsittacus undulatus & Psittaciformes & budgerigar & -0.016 & short \\
\hline Phasianus colchicus & Galliformes & ring-necked pheasant & -0.017 & short \\
\hline
\end{tabular}




\begin{tabular}{|c|c|c|c|c|}
\hline Ara macao & Psittaciformes & scarlet macaw & -0.020 & short \\
\hline Sterna nilotica & Aequorlitornithes (water birds) & gull-billed tern & -0.023 & short \\
\hline Larus argentatus & Aequorlitornithes (water birds) & European herring gull & -0.023 & short \\
\hline Pandion haliaetus & Accipitriformes & osprey & -0.027 & short \\
\hline Vultur gryphus & Accipitriformes & Andean condor & -0.028 & short \\
\hline Creagrus furcatus & Aequorlitornithes (water birds) & swallow-tailed gull & -0.030 & short \\
\hline Patagona gigas & Strisores - hummingbird & giant hummingbird & -0.030 & short \\
\hline Aythya fuligula & Anseriformes & tufted duck & -0.034 & short \\
\hline Archilochus colubris & Strisores - hummingbird & $\begin{array}{l}\text { ruby-throated } \\
\text { hummingbird }\end{array}$ & -0.035 & short \\
\hline Viavenator exxoni & Abelisauridae & (fossil species) & -0.035 & short \\
\hline Phoebastria immutabilis & Aequorlitornithes (water birds) & Laysan albatross & -0.046 & short \\
\hline Nestor notabilis & Psittaciformes & kea & -0.046 & short \\
\hline Fulmarus glacialis & Aequorlitornithes (water birds) & northern fulmar & -0.047 & short \\
\hline Sinraptor dongi & Allosauroidea & (fossil species) & -0.049 & short \\
\hline Ciconia nigra & Aequorlitornithes (water birds) & black stork & -0.050 & short \\
\hline Opisthocomus hoazin & hoatzin & hoatzin & -0.050 & short \\
\hline Selasphorus rufus & Strisores - hummingbird & rufous hummingbird & -0.055 & short \\
\hline Ramphastos dicolorus & Coraciimorphae & green-billed toucan & -0.057 & short \\
\hline Phaethon lepturus & Aequorlitornithes (water birds) & white-tailed tropicbird & -0.070 & short \\
\hline Strigops habroptila & Psittaciformes & kakapo & -0.073 & short \\
\hline Scolopax rusticola & Aequorlitornithes (water birds) & Eurasian woodcock & -0.075 & short \\
\hline Khaan mckennai & Oviraptorosauria & (fossil species) & -0.080 & short \\
\hline Apteryx haastii & Palaeognathae & great-spotted kiwi & -0.081 & short \\
\hline Pelagodroma marina & Aequorlitornithes (water birds) & white-faced storm petrel & -0.082 & short \\
\hline Apteryx australis & Palaeognathae & southern brown kiwi & -0.120 & short \\
\hline Conchoraptor gracilis & Oviraptorosauria & (fossil species) & -0.123 & short \\
\hline Struthiomimus altus & Ornithomimosauria & (fossil species) & -0.125 & short \\
\hline Struthio camelus & Palaeognathae & common ostrich & -0.151 & short \\
\hline Citipati osmolskae & Oviraptorosauria & (fossil species) & -0.191 & short \\
\hline
\end{tabular}

Table S3. Relative ECD lengths, rank-ordered from longest to shortest, listing species names and group memberships. Non-avialan theropod are known from fossil data and are shown in bold typeface. Qualitative elongation categories are assigned reflecting in-text descriptions. A distinct distributional gap is present between 'high elongation' and 'moderate elongation'. However, 'moderate elongation', 'limited elongation' and 'short' represent qualitative subdivisions of a quantitative continuum. 
Data Captions (for review purposes all separate files available at https://osf.io/gxvdc/?view only=e45e029daed24c50ada38ee1fbb2892d; to be replaced with DOI or other permanent link upon acceptance)

Data S1. A zipped folder containing 33 .stl models of living bird inner ears that are new to this study. Complete data for all reconstructed ears used in this study are also available at the following links:

For new models used in this study: https://www.morphosource.org/Detail/ProjectDetail/Show/project_id/1096

For previously published models (44) used in this study: http://www.morphosource.org/Detail/ProjectDetail/Show/project_id/377

Data S2. A zipped folder containing 17 .stl models of extinct theropod inner ears Data S3. A spreadsheet containing measured optical variables for all taxa analyzed Data S4. Spreadsheet containing taxonomic information, morphological measurements, specimen provenance/accession/voucher numbers, copyright information, and CT scan parameters for 74 extant bird and 17 extinct theropod inner ears

Data S5. A spreadsheet containing pp nocturnal values for each tree and each analysis iteration for Haplocheirus sollers

Data S6. A spreadsheet containing $\mathrm{pp}_{\text {nocturnal }}$ values for each tree and each analysis iteration for Megapnosaurus kayentakatae

Data S7. A zipped folder containing all data, trees, and R scripts to run SOR analysis, plus folders containing all results. A readme file explains how to run the scripts.

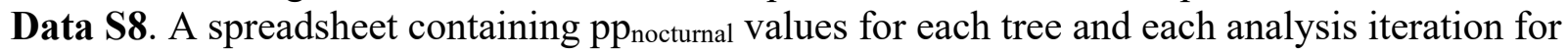
Shuvuuia deserti

Data S9. A spreadsheet containing classification summaries for phylogenetic flexible discriminant analyses, performed over a sample of 50 trees.

Data S10. A spreadsheet containing average classification errors for phylogenetic flexible discriminant analyses, broken down by group of diel activity pattern (dap).

Data S11. A spreadsheet containing predicted diel activity pattern from all analyses. 